\title{
Assessment on Time-Varying Thermal Loading of Engineering Structures Based on a New Solar Radiation Model
}

\author{
Bo Chen, ${ }^{1}$ Yu-zhou Sun, ${ }^{2}$ Gan-jun Wang, ${ }^{3}$ and Ling-yan Duan ${ }^{1}$ \\ ${ }^{1}$ Key Laboratory of Roadway Bridge and Structural Engineering, Wuhan University of Technology, Wuhan 430070, China \\ ${ }^{2}$ School of Civil Engineering and Architecture, Zhongyuan University of Technology, Zhengzhou 450007, China \\ ${ }^{3}$ Zhongshan Power Supply Bureau, Guangdong 528400, China \\ Correspondence should be addressed to Bo Chen; cbsteven@163.com
}

Received 25 December 2013; Revised 9 February 2014; Accepted 10 February 2014; Published 18 March 2014

Academic Editor: Ting-Hua Yi

Copyright (c) 2014 Bo Chen et al. This is an open access article distributed under the Creative Commons Attribution License, which permits unrestricted use, distribution, and reproduction in any medium, provided the original work is properly cited.

\begin{abstract}
This paper aims to carry out the condition assessment on solar radiation model and thermal loading of bridges. A modification factor is developed to change the distribution of solar intensities during a whole day. In addition, a new solar radiation model for civil engineering structures is proposed to consider the shelter effects induced by cloud, mountains, and surrounding structures. The heat transfer analysis of bridge components is conducted to calculate the temperature distributions based on the proposed new solar radiation model. By assuming that the temperature along the bridge longitudinal direction is constant, one typical bridge segment is specially studied. Fine finite element models of deck plates and corrugate sheets are constructed to examine the temperature distributions and thermal loading of bridge components. The feasibility and validity of the proposed solar radiation model are investigated through detailed numerical simulation and parametric study. The numerical results are compared with the field measurement data obtained from the long-term monitoring system of the bridge and they shows a very good agreement in terms of temperature distribution in different time instants and in different seasons. The real application verifies effectiveness and validity of the proposed solar radiation and heat transfer analysis.
\end{abstract}

\section{Introduction}

Civil engineering structures are subjected to long-term thermal effects induced by solar radiation and ambient air temperature. The structural components may receive heat energy from the direct radiation, diffuse radiation, and reflected radiation to cause seasonal and daily temperature changes $[1$, $2]$. The time varying thermal loadings in the structures may induce the structural deformation and thermal stresses due to the indeterminacy, which may cause the damage events of the components, even the entire structures $[3,4]$. Therefore, the thermal loading and thermal effects have attracted great attention across the world for the past decades. The thermal effects on civil engineering structures have been investigated to simulate the temperature distribution and predict the structural responses by using solar radiation model and heat transfer analysis with the aid of finite element (FE) method [5].

The temperature effects of civil engineering structures have been investigated extensively since the 1960s. The research on structural thermal effects has been firstly carried out in the early stages through field measurement and testing due to the limitation of theoretical approaches. Zuk [6] investigated the thermal behavior of several highway bridges and found that the temperature distribution was affected by many factors such as air temperature, wind, humidity, intensity of solar radiation, and material type. Capps [7] assessed the thermal effects of a steel box bridge in the UK through measuring structural temperature and longitudinal movements. Churchward and Sokal [8] carried out the condition assessment of structural thermal effects by testing temperature profiles at different time instants of a section of poststressed concrete bridge. In reality, it is widely accepted that the temperature distribution with a body is governed by heat conduction, heat convection, and solar radiation from the surrounding environment. In 1822, Fourier proved that the rate of heat transfer is proportional to the temperature gradients which can be depicted by the well-known Fourier partial differential equation. Nevertheless, the theoretical analyses of thermal loading and effects of civil engineering 
structures are quite rare due to the difficulties in large scale numerical computation. The investigations of structural temperature distribution and thermal effects have been substantially carried out since the 1970s with the rapid developments in computer techniques with the finite element method in the thermal analysis [9]. The pioneer work on the thermal effects of bridges dates back to Kehlbeck [10]. He proposed the theoretical approach for the thermal analysis and systematically examined the thermal effects of bridges. The thermal effects were investigated in detail by taking the solar radiation and surrounding convection into consideration. The detail parametric study is performed to examine the effects of solar radiation, convex, conduction, heat of hydration, member size and geometry, and so forth. Elbadry and Ghali [11] examined the temperature distribution and estimated stresses of a concrete bridge by developing a two-dimensional finite element model. Branco and Mendes [12] proposed an approach to define temperature design values for concrete bridges.

In the past two decades, the field measurement and monitoring of temperature distribution and thermal effects of civil engineering structures have been widely carried out due to the rapid development and application of structural health monitoring (SHM) system and technology [13-15]. Shahawy and Arockiasamy [16] compared the measured time-dependent strains of the Sunshine Skyway Bridge with the analytical predictions. Fu and DeWolf [17] carried out field measurement and numerical simulation on a curved concrete bridge concerning the temperature effects on the tilt and natural frequencies. Xu et al. [18] investigated the temperature-induced displacement responses of Tsing $\mathrm{Ma}$ Bridge based on field monitoring data from 1997 to 2005 . Xia et al. [19] examined the temperature effect on vibration properties of civil structures by taking a concrete structure, the Tsing Ma Suspension Bridge, and the Guangzhou New TV tower as example structures. Xia et al. [20] investigated the temperature distribution in a long span suspension bridge through finite element analysis. Similar studies in the field include those of Wong et al. [21, 22], Tong et al. [23], Au et al. [24], Roberts-Wollman et al. [25], and Desjardins et al. [26].

Current investigation mainly focuses on the thermal deformation and the effects of small concrete bridges. The configurations and performance of long span bridges such as suspension bridges are quite different from those of common concrete bridges. In addition, the solar radiation model in the field of astronomy is directly utilized in the thermal analysis civil engineering structures. It is reported that the thermal loading and the effect of large scale structures are different due to the shelter effects of the solar radiation. The collected data from health monitoring system indicate that the measured temperature distribution does not agree with that from the field measurement. Consequently, the solar radiation model and heat transfer analysis techniques suitable for the civil engineering structures are expected. In this regard, the condition assessment of solar radiation model and thermal loading of bridges are actively carried out in this study. A modification factor is developed to change the distribution of solar intensities during a whole day. Furthermore, a new solar radiation model for civil engineering structures is proposed to consider the shelter effects induced by cloud, mountains, and surrounding structures. The heat transfer analysis of bridge components is conducted to calculate the temperature distributions based on the proposed new solar radiation model. By assuming that the temperature along the bridge longitudinal direction is constant, one typical bridge segment is specially studied. Fine finite element models of deck plates and corrugate sheets are constructed to examine the temperature distributions and thermal loading of bridge components. The feasibility and validity of the proposed solar radiation model are investigated through detailed numerical simulation and parametric study. The numerical results are compared with the field measurement data obtained from the long-term monitoring system of the bridge and it shows a very good agreement, in terms of temperature distribution in different time instants and in different seasons. The real application verifies effectiveness and validity of the proposed solar radiation and heat transfer analysis.

\section{Solar Radiation Effect}

2.1. Solar Radiation Model. The rate of heat absorbed by the bridge surface due to solar radiation $q_{s}$ is [27]

$$
q_{s}=\alpha I,
$$

where $\alpha(0<\alpha<1)$ is absorptivity coefficient of the surface material and $I$ is solar radiation including direct solar radiation, diffuse solar radiation, and reflected solar radiation on a surface, respectively.

The spatial position of the sun and bridge is displayed in Figure 1, where $\psi$ is solar altitude; $\theta$ is the incidence angle of sun rays; $\gamma_{s}$ is the azimuth angle; vector $\vec{n}$ is perpendicular to the surface; surface azimuth angle $\gamma$ is measured from the south, positively toward the west; and $\beta$ is the tilt angle from the horizontal, which is positive for south-facing surfaces; the solar incidence angle $\theta$ is defined as the angle between the surface normal $\vec{n}$ and a line collinear with the sun's rays.

The solar radiation is affected by several factors such as the hour of the day, the day of the year, the latitude and the altitude of the bridge, and the cloudiness of the sky. The radiation can be simulated considering analytical expressions for the effects of these factors or considering the evolution during any day as a function of the maximum daily radiation. The direct and indirect solar radiation on a surface can be computed separately in order to consider the evolution of the shadow zones during the day and the effects of surface tilt angle $[12,27]$. Consider

$$
I=I_{d}+I_{i}+I_{r}
$$

in which $I_{d}, I_{i}$, and $I_{r}$ are the direct solar radiation, diffuse solar radiation, and reflected solar radiation on a surface, respectively. In reality, the information of direct, diffuse, and reflected solar radiation on the ground can be obtained through field measurement or simulation. Then, $I_{d}, I_{i}$, and $I_{r}$ can be determined by considering the tilt angle of the surface.

2.2. Solar Radiation Component. The direct radiation energy to heat up the bridge structure depends on the solar constant 


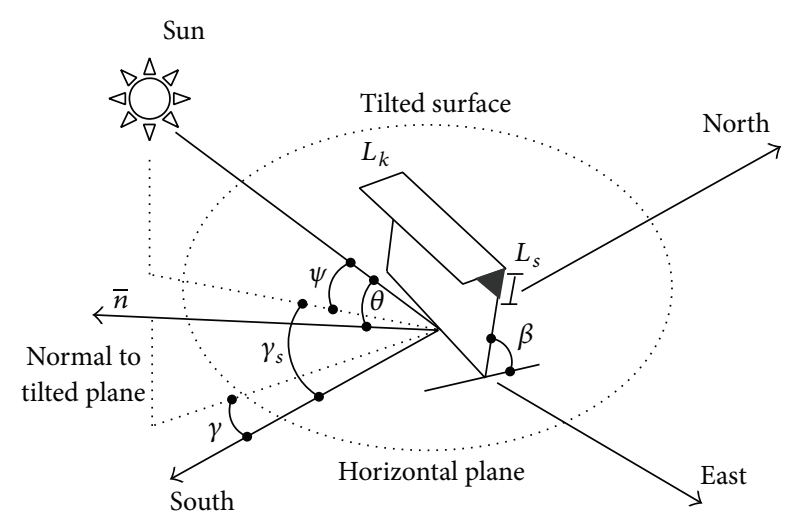

FIGURE 1: Definition of spatial position of the sun and structure.

$I_{\mathrm{sc}}$ and the absorption of the solar energy in the atmosphere. The earth's atmosphere acts as a filter for the solar radiation so that only a fraction of the total solar radiation reaches the surface of the earth. The energy reaching the earth's surface by direct radiation can be expressed by

$$
I_{d 0}=I_{\mathrm{sc}} K_{T}
$$

in which $K_{T}$ denotes the transmittance factor and depends on the atmospheric conditions and the length of the path the radiation has to travel through the air mass. $K_{T}$ expresses the scatter of the light in a pure atmosphere, as well as the absorption of certain wave lengths by the atmosphere. When the sun rays make an incidence angle $\theta$ with the normal to the surface, the rate of the bridge tower radiation of bridge tower becomes

$$
I_{d}=I_{d 0} \cos \theta=I_{\mathrm{sc}} K_{T} \cos \theta .
$$

The direct solar radiation is accompanied by radiation that has been scattered or remitted, called diffuse solar radiation. The energy reaching the earth's surface by diffuse solar radiation can be estimated using Berlage's equation

$$
I_{i 0}=\frac{1}{2} \cdot \frac{1-P^{m}}{1-1.4 \ln P} I_{\mathrm{sc}} \sin \psi
$$

in which

$$
P=0.9^{k_{a} t_{u}}
$$

where $k_{a}$ is the ratio of atmospheric pressure to pressure at sea level and $t_{u}$ is turbidity factor which is used to express the attenuation of radiation in different atmospheric conditions.

The direct and diffuse solar radiation may also be reflected onto a surface from nearby surfaces which is the socalled reflected solar radiation

$$
I_{r 0}=r_{e}\left(I_{d}+I_{i 0}\right),
$$

where $r_{e}$ is the reflected coefficient of ground. The reflected solar radiation on a surface with tilt angle $\beta$ is

$$
I_{r}=\frac{1-\cos \beta}{2} I_{r 0}
$$

\section{New Solar Radiation Model}

3.1. Solar Radiation. The duration in which the bridge component can receive solar radiation in one day is expressed as

$$
t_{\text {solar }}=t_{\mathrm{ss}}-t_{\mathrm{sr}}
$$

in which $t_{\text {ss }}$ and $t_{\text {sr }}$ are corresponding hours of sunset and sunrise, respectively. The peak solar radiation is observed at time $t_{p 0}$

$$
t_{p 0}=t_{\text {sr }}+\frac{t_{\text {solar }}}{2} .
$$

In the traditional solar radiation models, the hour with peak solar radiation intensity $t_{p 0}$ is very close to $12: 00 \mathrm{pm}$, and the solar radiation intensity before and after peak solar intensity hour $t_{p 0}$ is almost the same. This assumption may differ from the practical situation due to the diversity of cloud shading and topographical features. For instance, the field measurement on Tsing Ma Suspension Bridge shows that the hour with peak solar intensity $t_{p 0}$ in summer is about $13: 00 \mathrm{pm}$ and the solar intensity before time $t_{p 0}$ is smaller than that over time $t_{p 0}$. In this regard, the solar radiation model is modified here to simulate the solar radiation on bridges. In the modified model, the ratio of solar radiation intensity before and after the peak solar radiation time is revised while the total solar radiation intensity in one day remains unchanged. The modification factor $c$ is defined as the combination of sinusoidal functions

$$
c= \begin{cases}\frac{\sin ^{p}\left(\pi\left(t-t_{\mathrm{sr}}\right) / t_{k 1}\right)}{\sin \left(\pi\left(t-t_{\mathrm{sr}}\right) / t_{\mathrm{solar}}\right)} & t_{\mathrm{sr}}<t \leq t_{p} \\ \frac{\sin ^{1 / q}\left(\pi\left(t-t_{\mathrm{ss}}+t_{k 2}\right) / t_{k 2}\right)}{\sin \left(\pi\left(t-t_{\mathrm{sr}}\right) / t_{\text {solar }}\right)} & t_{p}<t \leq t_{\mathrm{ss}},\end{cases}
$$

in which

$$
\begin{gathered}
t_{k 1}=t_{\mathrm{ss}}-t_{\mathrm{sr}}+2\left(t_{p}-t_{p 0}\right), \\
t_{k 2}=2\left(t_{\mathrm{ss}}-t_{p}\right),
\end{gathered}
$$

in which $t$ denotes hour in a day and $p$ and $q$ are two positive exponential parameters for modulating the solar intensity ratio before and after $t_{p}$. The total solar radiation intensity in a day for the original prediction model can be obtained by summarizing the solar intensities at all the hours

$$
S_{I}=\sum_{i=t_{\mathrm{sr}}}^{t_{\mathrm{ss}}} I^{i} .
$$

The total solar radiation intensity in a day for the modified prediction model is

$$
S_{I}^{m}=\sum_{i=t_{\mathrm{sr}}}^{t_{\mathrm{ss}}} c_{i} I^{i} .
$$

The difference ratio between the original and modified prediction models is

$$
S_{\mathrm{err} 0}=\frac{S_{I}^{m}-S_{I}}{S_{I}^{m}} .
$$


To keep the total daily solar intensity unchanged, the modified solar intensity is $I_{m}$

$$
I_{m}=I \cdot c \cdot\left(1-S_{\mathrm{err} 0}\right)
$$

It is observed that the modification factor $c$ indicated in (11) is the combination of many sinusoidal functions. By changing the properties of the sinusoidal function, the values of modification factor $c$ before and after $t_{p}$ may alter, which may thereby lead to the changes in solar radiation intensity before and after $t_{p}$. To demonstrate the effectiveness of modification parameter $c$, a sine function is utilized for numerical indication as follows:

$$
f(x)=\sin \frac{\pi\left(t-t_{\mathrm{sr}}\right)}{t_{\text {solar }}} \quad\left(t_{\mathrm{sr}}<t<t_{\mathrm{ss}}\right) .
$$

The date for calculating parameters in (11), such as $t_{\text {solar }}$, $t_{\mathrm{ss}}$, and $t_{\mathrm{sr}}$, is July, 17, 2005. The time instant of peak solar radiation hour $t_{p}$ is assumed as 13:00 pm. Figure 2 shows the modification factor $c$ with different parameters. It is observed that the application of modification parameter $c$ can change the solar intensity ratio before and after the peak solar radiation hour $t_{p}$. Different $p$ and $q$ can alter the distribution of daily solar intensity of a structure at a certain place. Relatively large $p$ and $q$ may cause the smaller solar radiation intensity before $t_{p}$ and vice versa. It is noted that the actual peak solar radiation hour $t_{p}$ and two parameters, $p$ and $q$, can be determined based on direct measurement of solar intensities or be numerically estimated based on the measured temperature information of structural components with direct solar radiation.

3.2. Boundary Condition for Heat Transfer Analysis. The flow of heat in a solid is governed by the well-known Fourier equation. For a bridge component subjected to solar radiation, it can be assumed that there is no thermal variation along the bridge longitudinal direction [11, 17]. Consequently, the temperature field $T$ of a bridge cross-section at any time can be expressed by a two-dimensional heat flow equation as

$$
k\left(\frac{\partial^{2} T}{\partial x^{2}}+\frac{\partial^{2} T}{\partial y^{2}}\right)+q=c \rho \frac{\partial T}{\partial t},
$$

in which $k$ is the isotropic thermal conductivity coefficient, $\rho$ is the density of material, $c$ is the heat of the material, and $q$ denotes the rate of heat transferred between the surface and the environment. The thermal energy transferred between the bridge surface and the environment consists of convection $q_{c}$, thermal irradiation $q_{r}$, and solar radiation $q_{s}$

$$
q=q_{c}+q_{r}+q_{s}
$$

The rate of heat transfer by convection $q_{c}$ is associated with the movement of the air particles and depends on the convection heat transfer coefficient $h_{c}$ and difference between the air temperature $T_{a}$ and the bridge surface temperature $T_{s}$.

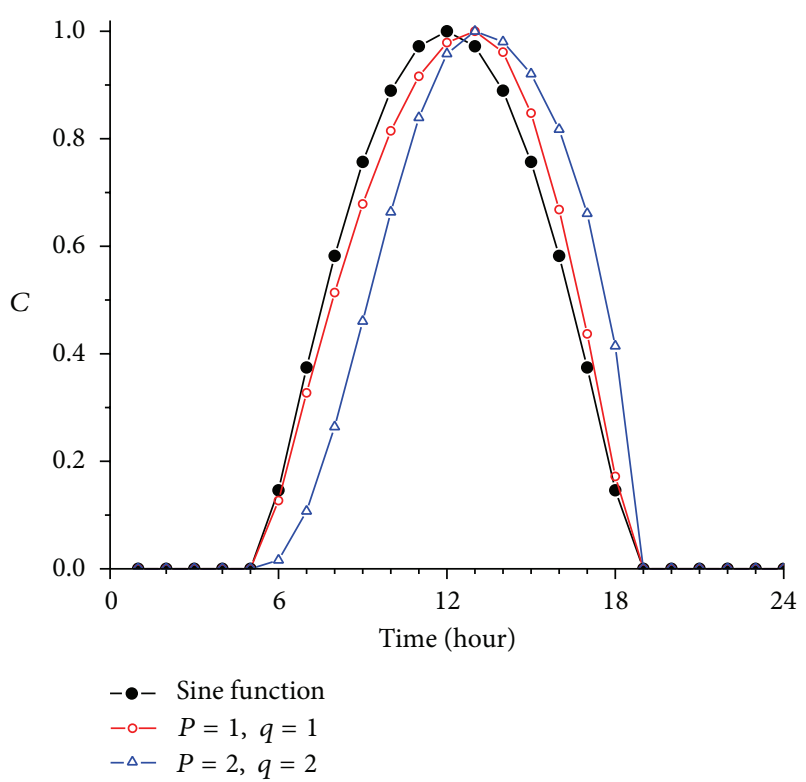

Figure 2: Comparison of modification factor $c$.

The energy transferred between the surface elements and the environment can be expressed as

$$
\begin{gathered}
q=h\left(T^{*}-T_{s}\right), \\
T^{*}=T_{a}+\frac{\alpha I_{m}}{h},
\end{gathered}
$$

where $h$ is the heat transfer coefficient.

\section{Bridge Configuration and Health Monitoring System}

The Tsing Ma Bridge is a suspension bridge with an overall length of $2160 \mathrm{~m}$ and a main span of $1377 \mathrm{~m}$ (see Figure 3). It carries a dual three-lane highway on the upper level of the deck and two railway tracks and two carriageways on the lower level within the deck box. The box deck is of a hybrid steel structure that is $41 \mathrm{~m}$ wide and $7.643 \mathrm{~m}$ high. The height of the two reinforced concrete bridge towers is about $206 \mathrm{~m}$. The lengths of the Tsing Yi side span and the Ma Wan side span are $300 \mathrm{~m}$ and $455 \mathrm{~m}$, respectively. The structural translational movements at the Ma Wan abutment are restrained in three translational directions. At the Tsing Yi abutment, the vertical ( $z$-axis) and lateral ( $y$-axis) movements of the bridge deck are restrained while the deck can move freely along the longitudinal direction ( $x$-axis). The bridge deck at the main span is a suspended deck and the structural configuration is typical for every $18 \mathrm{~m}$ segment. The major structural components of $18 \mathrm{~m}$ deck module include a main cross frame and four neighboring intermediate cross frames. Two symmetrical bays of top orthotropic deck plates (left and right) are connected to the top chords of cross frames. Two railway tracks lay on the central bay of the deck in addition to two bays of orthotropic deck plates on the two outer sides that are all supported on the bottom chords of cross frames. 


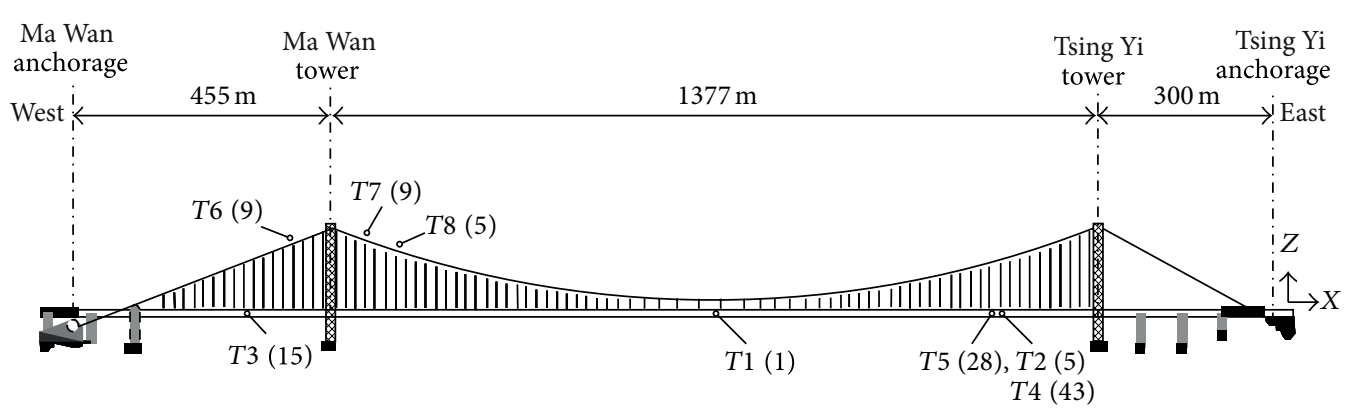

FIgURE 3: Bridge configuration and distribution of temperature sensors.

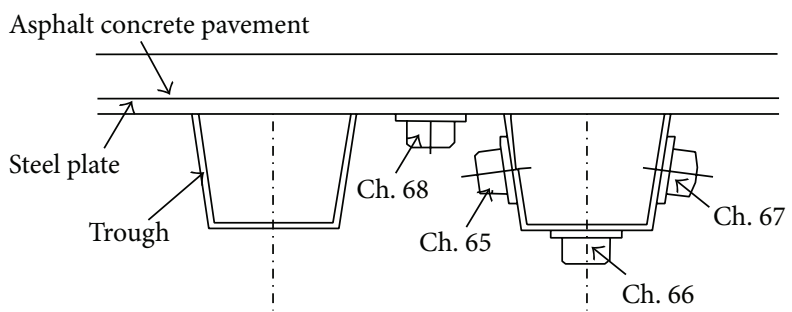

FIGURE 4: Location of temperature sensors for deck plate at Detail 12.

The detailed introduction on the configuration of a typical suspended deck module can be referred to [5].

A Wind and Structural Health Monitoring System (WASHMS) for the Tsing Ma Bridge has been devised, installed, and operated since 1997. About 280 sensors were installed on the bridge to monitor the loading and structural responses. 115 temperature sensors are divided into three categories to measure the ambient and structural temperature information as shown in Figure 3: (1) ambient temperature ( $T 1$ and $T 2) ;(2)$ section temperature (T3, T4, and T5); and (3) cable temperature ( $T 6, T 7$, and $T 8$ ). The sensor with signal channel number of $81(T 1)$ is located in the middle of the main span and the other five air temperature sensors (Ch. 82 to Ch. $86, T 2)$ are mounted at a section close to Tsing Yi tower. There are seven groups of temperature sensors (Details numbers 10 to 16,28 sensors in total) mounted on the orthotropic deck plates $2.25 \mathrm{~m}$ away from the section. At each detail, one sensor measures the temperature of steel plate and the other three sensors measure the temperature distribution over the deck trough as shown in Figure 4. The sampling frequency of all of the temperature sensors is $0.07 \mathrm{~Hz}$ [5].

\section{Thermal Loading and Temperature Distribution}

5.1. Model and Parameter of Deck Plate. Thermal variation of the bridge deck in the longitudinal direction of the bridge can be assumed insignificant and thus one typical segment can be taken as example (Chen et al., 2013). The deck plate consists of steel deck plates, asphalt concrete cover, and deck troughs as shown in Figure 4. The thickness of the upper and lower deck plates is $13 \mathrm{~mm}$ while the counterparts for upper deck trough and lower deck trough are $8 \mathrm{~mm}$ and $10 \mathrm{~mm}$ thick,
TABLE 1: Thermal properties of material.

\begin{tabular}{lccc}
\hline Parameters & Asphalt & Concrete & Steel \\
\hline$k(\mathrm{~W} /(\mathrm{m} \cdot \mathrm{C})):$ thermal conductivity & 2.50 & 1.54 & 55 \\
$\rho\left(\mathrm{kg} / \mathrm{m}^{3}\right):$ density & 2100 & 2400 & 7800 \\
$c(\mathrm{~J} /(\mathrm{kg} \cdot \mathrm{C}))$ : heat capacity & 960 & 950 & 460 \\
$\alpha$ : absorptivity coefficient & 0.90 & 0.65 & 0.685 \\
$\varepsilon$ : emissivity coefficient & 0.92 & 0.88 & 0.80 \\
\hline
\end{tabular}

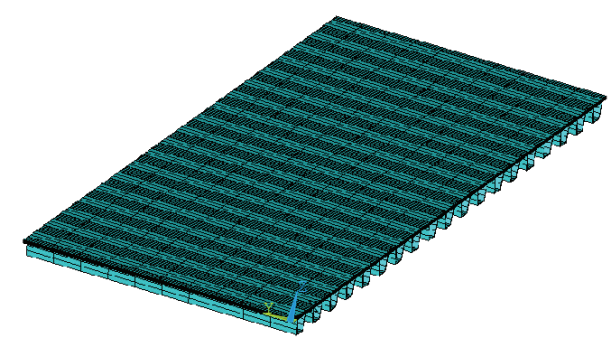

FIGURE 5: Finite element of a typical deck plate.

respectively. The steel deck plates are covered by $40 \mathrm{~mm}$ thick asphalt concrete. The finite element model of a typical deck plate is established using three-dimensional thermal elements by using the commercial package $[28,29]$ as shown in Figure 5 . The thermal properties of materials utilized in heat transfer analysis are listed in Table 1.

5.2. Temperature Distribution of Deck Plate in the Summer. The variations of hourly mean ambient temperature collected in channel 81 in year 2005 are displayed in Figure 6(a). In addition, variations of hourly mean ambient temperature for all the six ambient temperature sensors at July, 17, 2005, are 


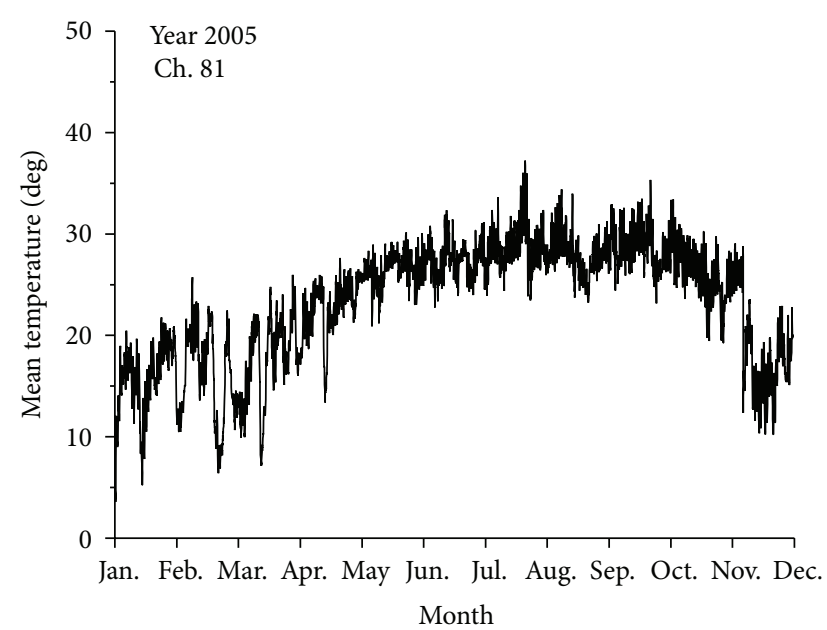

(a) Year 2005
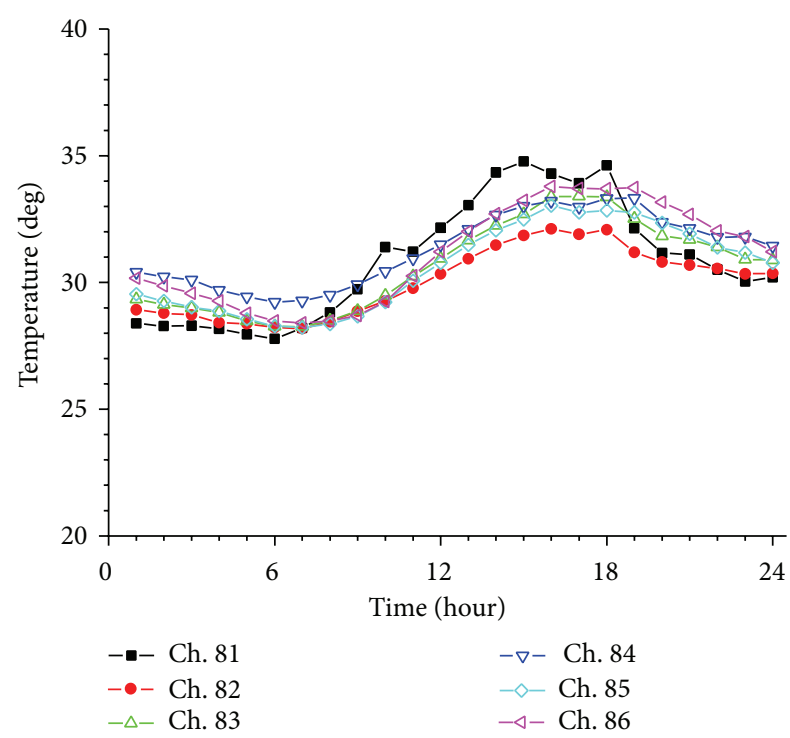

(b) July, 17, 2005

FIgURE 6: Variation of hourly mean ambient temperature.

examined for investigating the effects of sensor locations on the ambient temperature as shown in Figure 6(b). It is seen that all curves show similar variation trends despite their different location. It is observed that the ambient temperature out of bridge deck section (ch. 81) is larger than that within the deck section (chs. 82, 83) during the day and smaller than those in the night. The ambient temperature of ch. 83 is larger than that of ch. 82 for all the day because ch. 83 is more close to top plates receiving solar radiation. To compare the variation of ambient temperature in deck width, one can find that the temperature variation trends in different lateral positions are quite similar. The mean temperature of sensors close to the south deck plate is a little larger than that close to north plates due to the effects of thermal conductivity induced by solar radiation. The transient heat transfer analysis is carried out to determine the temperature distribution of the deck plate based on the actual thermal boundary conditions. The convection heat transfer coefficient can be computed in line with the wind speed and geometric configuration of deck plate by using an empirical formula [23]. The variation of solar intensity of Tsing Ma Bridge is observed and the field measurement indicates that the peak temperature hour is at about 13:00 pm in summer [18]. Therefore, the hour $t_{p}$ for peak temperature is set as 13:00 pm and the two parameters $p$ and $q$ are set as 5 and 5, respectively, for the new solar radiation model. The comparisons of solar intensities of the original radiation model and new radiation model for four seasons are displayed in Figure 7.

The calculated temperature of the deck plate of Detail 12 on July, 17, 2005, is compared with the measurement counterparts (Ch. 66 to Ch. 68) shown in Figure 8. It is observed that the variation trend of temperature obtained with the original radiation model is similar to that of the field measurement, while the peak temperature occurs a little earlier than the measurement by about 2 hours. This
TABLE 2: Peak temperature of the deck plate on July, 17, 2005 (Unit: $\left.{ }^{\circ} \mathrm{C}\right)$.

\begin{tabular}{lcccc}
\hline Component & \multicolumn{2}{c}{ Minimum } & \multicolumn{2}{c}{ Maximum } \\
& Measured & Simulated & Measured & Simulated \\
\hline $\begin{array}{l}\text { Bottom of trough } \\
\text { (Ch. 66) }\end{array}$ & 27.70 & 28.26 & 41.96 & 40.83 \\
$\begin{array}{l}\text { Middle of trough } \\
\text { (Ch. 67) }\end{array}$ & 27.58 & 28.27 & 45.74 & 44.74 \\
$\begin{array}{l}\text { Deck plate } \\
\text { (Ch. 68) }\end{array}$ & 27.12 & 28.25 & 49.95 & 51.28 \\
\hline
\end{tabular}

indicates that the peak solar radiation used in the model might occur earlier than the practical one. By using the new radiation model proposed in this paper, the simulated temperature at the three points agrees with the measurement very well at all time points, which validates the effectiveness of the proposed solar radiation model and the heat transfer analysis. Table 2 lists the peak temperature of the deck plate on July, 17, 2005 (Unit: ${ }^{\circ} \mathrm{C}$ ). It is observed that the simulated results are quite close to those from field measurement. The maximum temperature of the bottom of the deck plate is larger than that of steel trough. This is because the top surface of deck plate receives direct solar radiation and the maximum temperature is dominantly controlled by the solar radiation as well as the ambient temperature. Nevertheless, the minimum temperatures are observed at night and no solar radiation acts on the bridge components. Therefore, the minimum temperature at different parts of the deck plate is quite close to each other.

5.3. Temperature Distribution of Deck Plate in Other Seasons. The temperature variations of the deck plate in the other three seasons are also calculated and compared with those from 


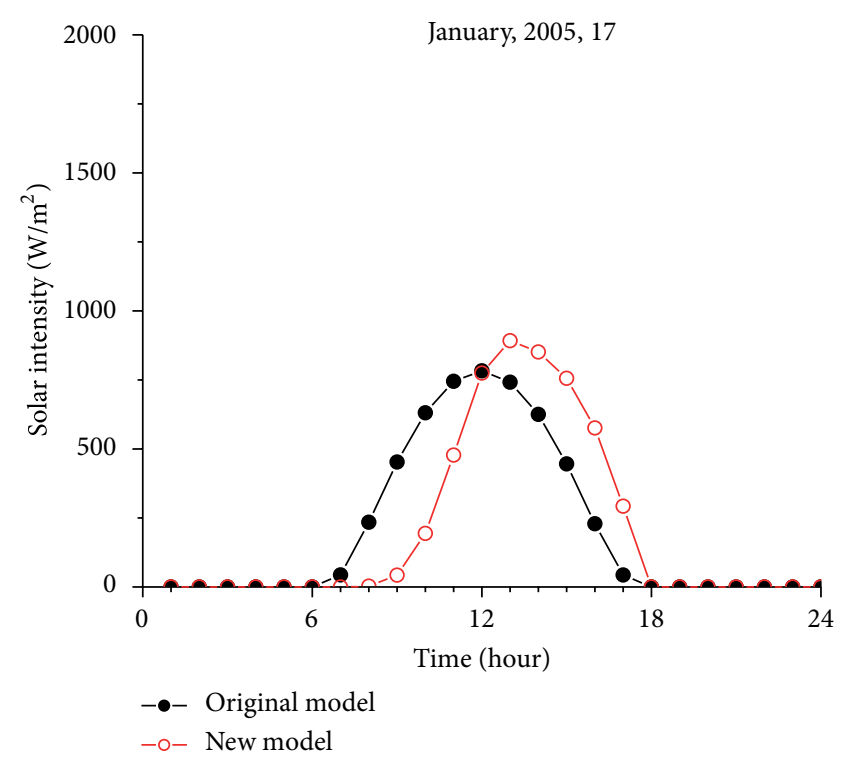

(a)

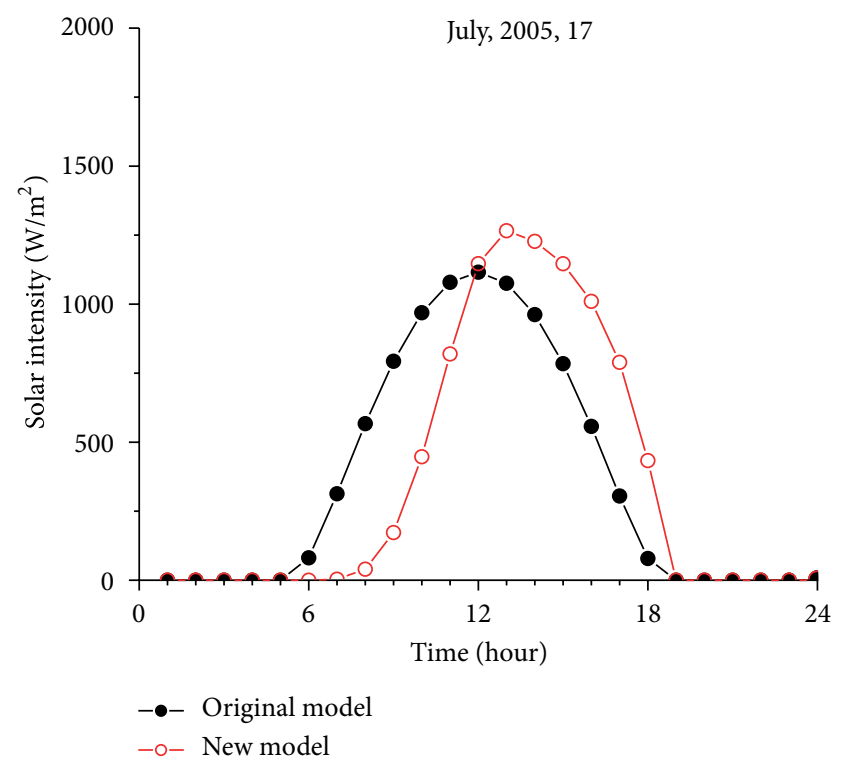

(c)

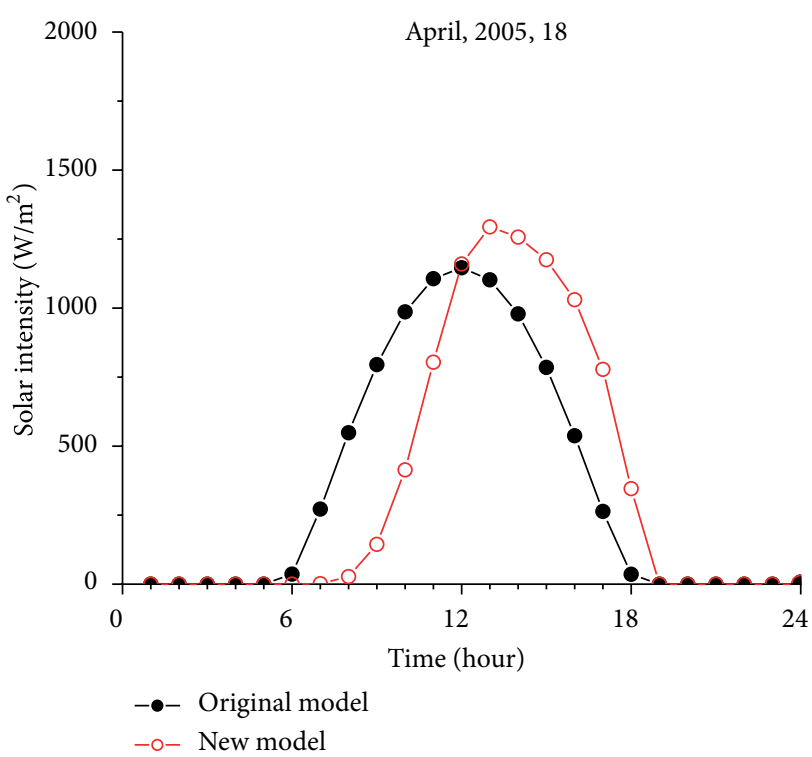

(b)

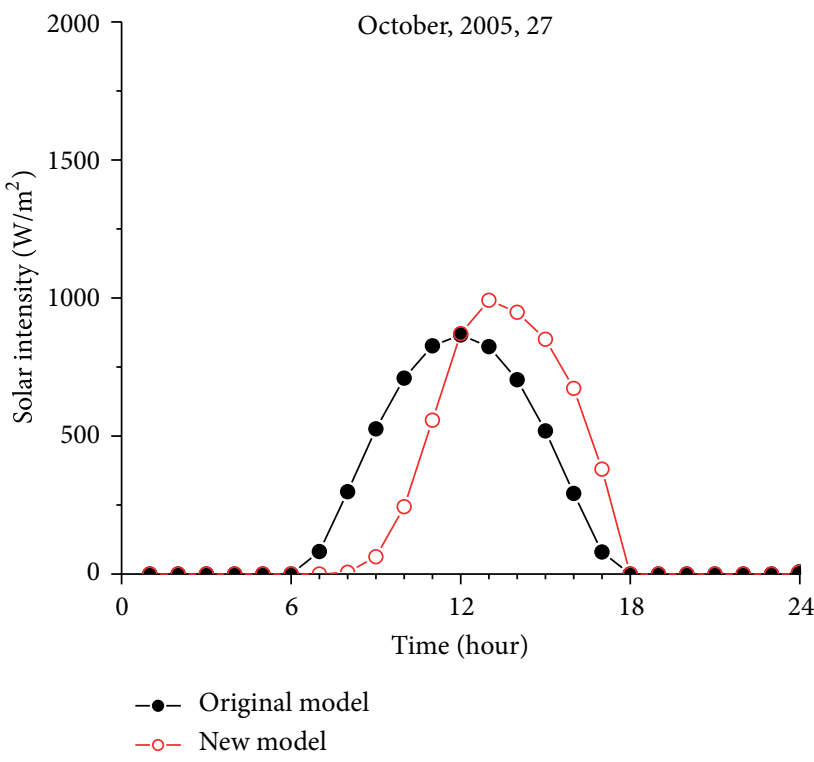

(d)

FIGURE 7: Variation of solar intensity of deck plates.

field measurement. The parameters of the improved radiation model are the same as those adopted in summer calculations except that the radiation intensity varies in different seasons. The temperature distributions of the deck plate based on the original and new solar radiation models are analyzed and compared as shown in Figure 9. It is observed that the peak temperature occurs at about $16: 00 \mathrm{pm}$ while the time for the simulated peak temperature using the original model is about 14:00 pm. Similar to the observations made for the summer day, the simulated temperature distributions using the new solar radiation model agree well with those from field measurement in comparison with those using the original solar radiation model.
The same conclusion can be drawn out from the temperature variations of the deck plate in the spring and winter as shown in Figures 10 and 11, respectively. It is found that the variation trend of temperature obtained with the original radiation model is similar to that of the field measurement in both spring and autumn. However, the peak temperatures are observed several hours earlier than the actual one based on filed measurement data. The simulated temperature variation at the three positions of the deck plate agrees with the measured data very well for the whole day. Therefore, the validity of the new solar radiation model can be proved through the comparison between the measured and simulated results. Similar to the summer day, the temperature 


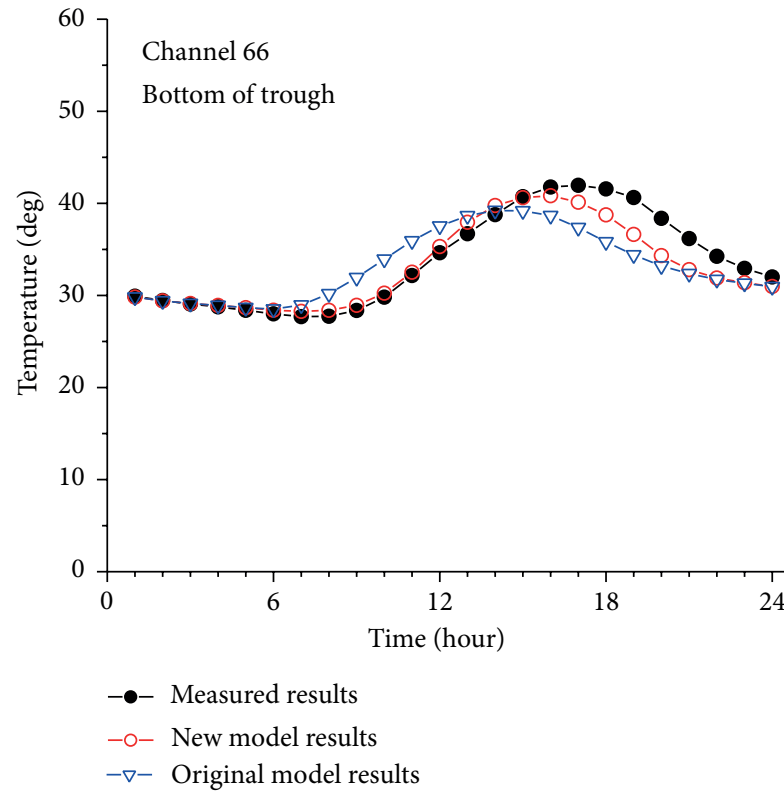

(a)

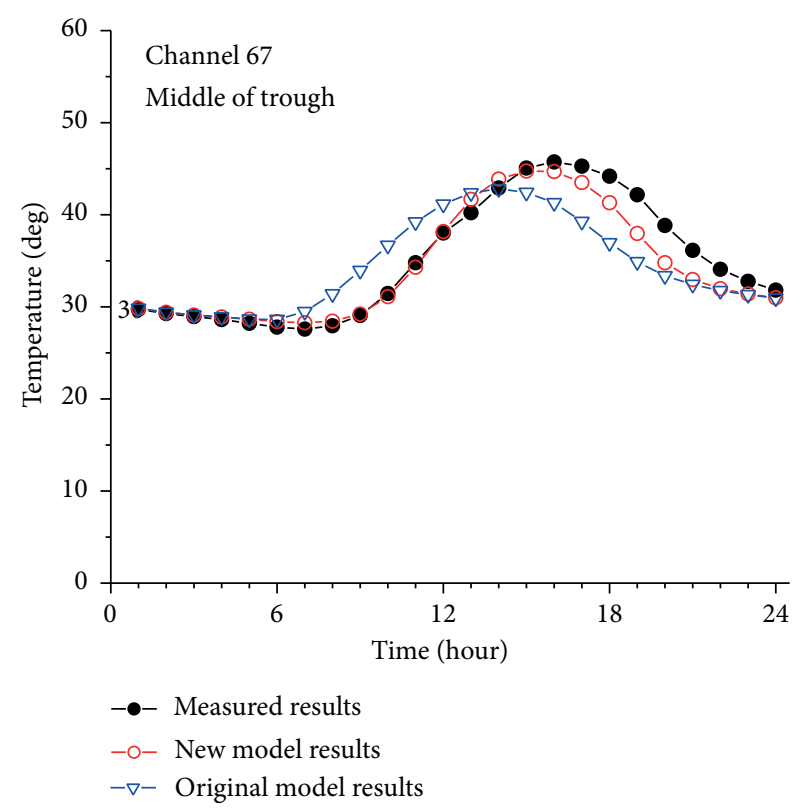

(b)

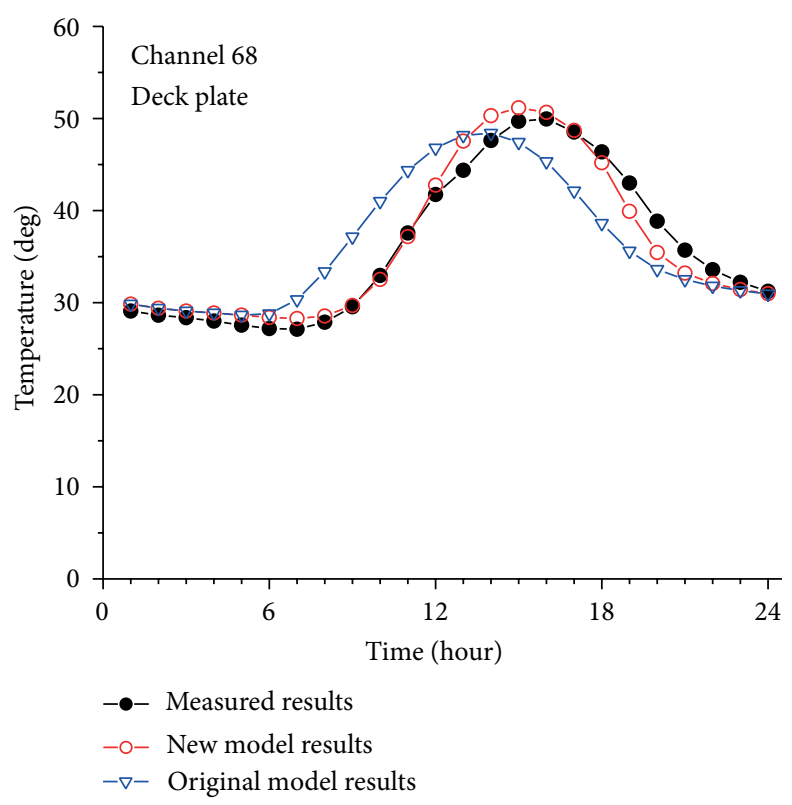

(c)

Figure 8: Comparison of the measured and simulated temperature in summer (July, 17, 2005).

variations in other seasons based on the new solar radiation model agree well with the measurement better than those from the original solar radiation model. The temperature distribution of the bridge plate at other deck details has also been obtained and it shows that the new solar radiation model can remarkably improve the simulation results. The comparison is not shown here for brevity.

5.4. Temperature Gradient of Deck Plate. The simulated temperature gradients of the deck plate at Detail 12 in different seasons are summarized and displayed in Figure 12.
It is observed that the temperature of the asphalt concrete cover can reach as high as about $61^{\circ} \mathrm{C}$ in the summer. The temperature of the asphalt concrete cover is much higher than that of the steel plate and the difference in the afternoon can be as high as $11^{\circ} \mathrm{C}$ in the summer. The difference of temperature between the top and bottom of the steel plate is small during the whole day. This is because the thermal conductivity of steel is much higher than that of the asphalt.

Similar observations can be made from the temperature gradients of the deck plate in spring, autumn, and winter, respectively. Listed in Table 3 is the peak temperature of the 


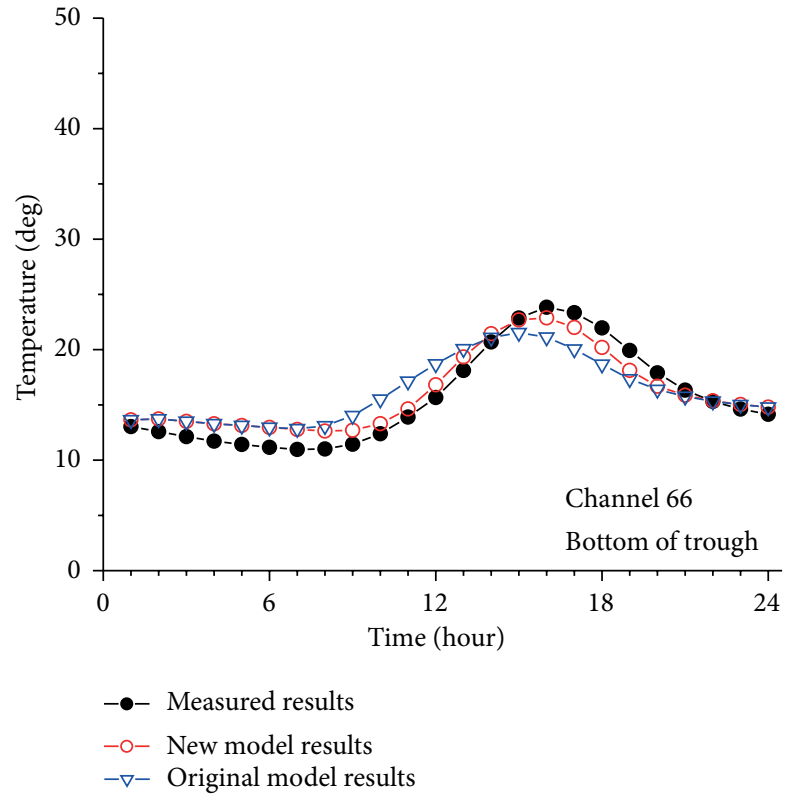

(a)

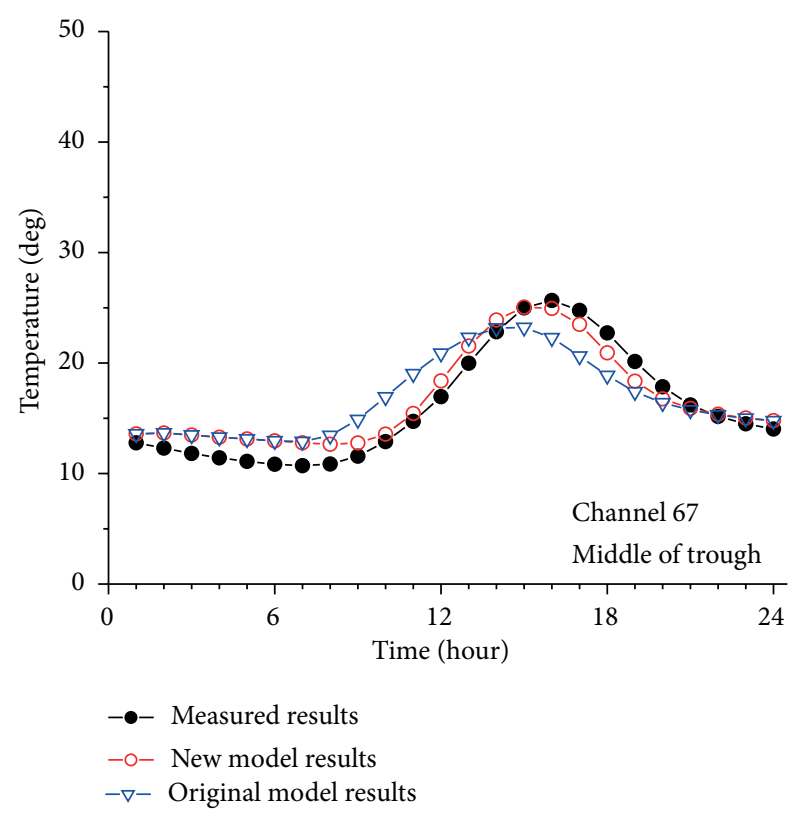

(b)

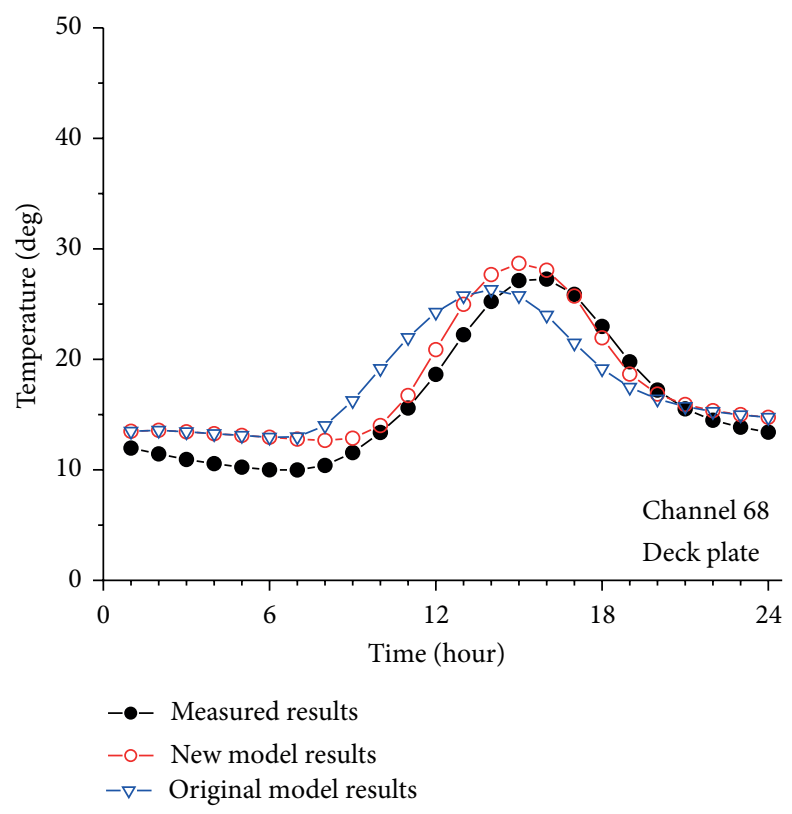

(c)

FIGURE 9: Comparison of the measured and simulated temperature in winter (January, 17, 2005).

deck plate in different seasons. The peak temperature of the asphalt concrete cover is larger than that of interface by about $10.5^{\circ} \mathrm{C}$ in the summer day. The temperature variation ranges of the cover surface and bottom plate in the summer day are $33.3^{\circ} \mathrm{C}$ and $22.5^{\circ} \mathrm{C}$, respectively. The difference of peak temperature between the top and bottom of steel plate is only about $0.08^{\circ} \mathrm{C}$ in the summer day. It is also seen that the time for minimum and maximum temperature of the cover is 6:00 am and 15:00 pm, respectively. The temperature differences in the other three seasons are smaller than those in the summer as displayed in Table 3. No matter which season is considered, the temperature gradients of the steel plate in the vertical direction are quite small.

5.5. Temperature Distribution of Other Bridge Components. Similar to the deck plate at Detail 12, the heat transfer analysis of other bridge components such as deck plates on the upper chord and bottom chord and the corrugated sheets is also carried out. Many detailed finite element models of these components are constructed by using three-dimensional thermal analytical elements. The corrugated sheets are modelled based on the design with minor simplification due to 
TABLE 3: Peak temperature of the deck plate in different seasons (unit: ${ }^{\circ} \mathrm{C}$ ).

\begin{tabular}{lcccc}
\hline Component & Spring & Summer & Autumn & Winter \\
\hline Top of asphalt cover & 52.14 & 61.85 & 52.04 & 33.01 \\
Middle of asphalt cover & 48.94 & 56.91 & 43.52 & 29.47 \\
Interface of cover and plate & 46.02 & 51.36 & 43.45 & 26.48 \\
Middle of steel plate & 45.93 & 51.32 & 43.27 & 26.43 \\
Bottom of steel plate & 45.68 & 51.28 & 26.31 \\
\hline
\end{tabular}

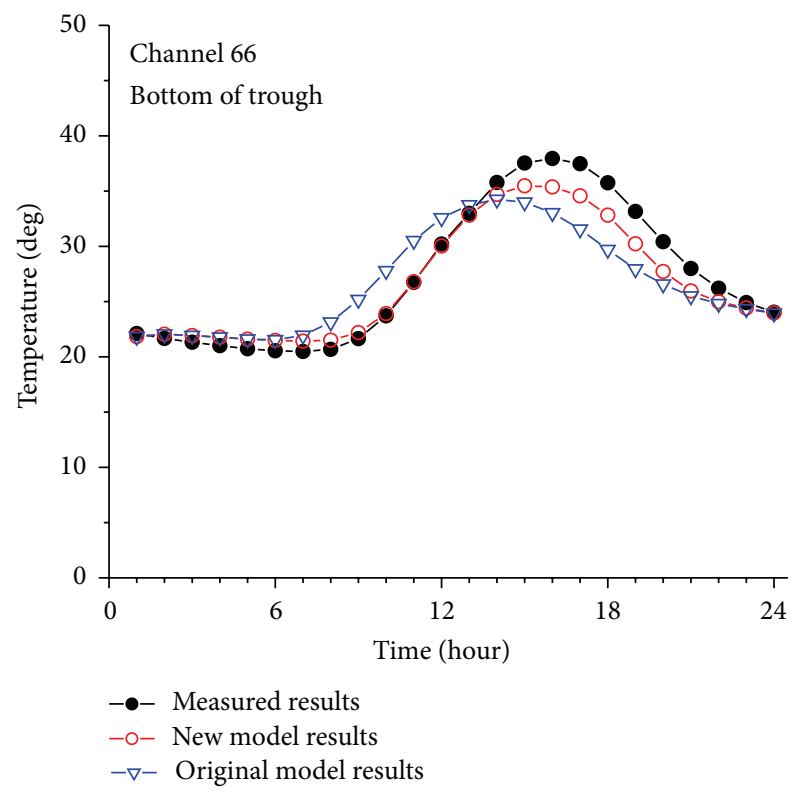

(a)

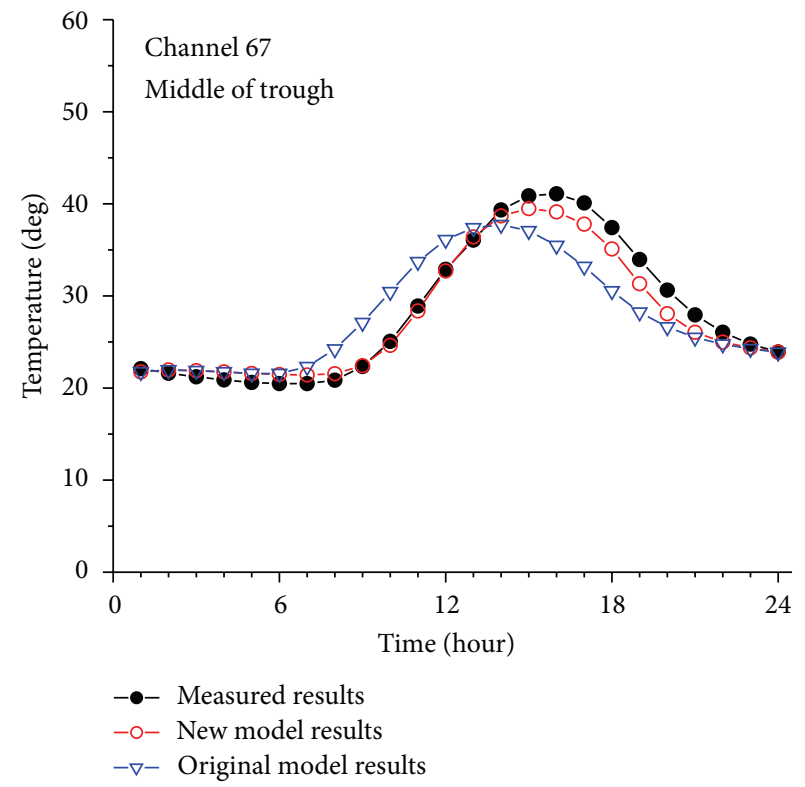

(b)

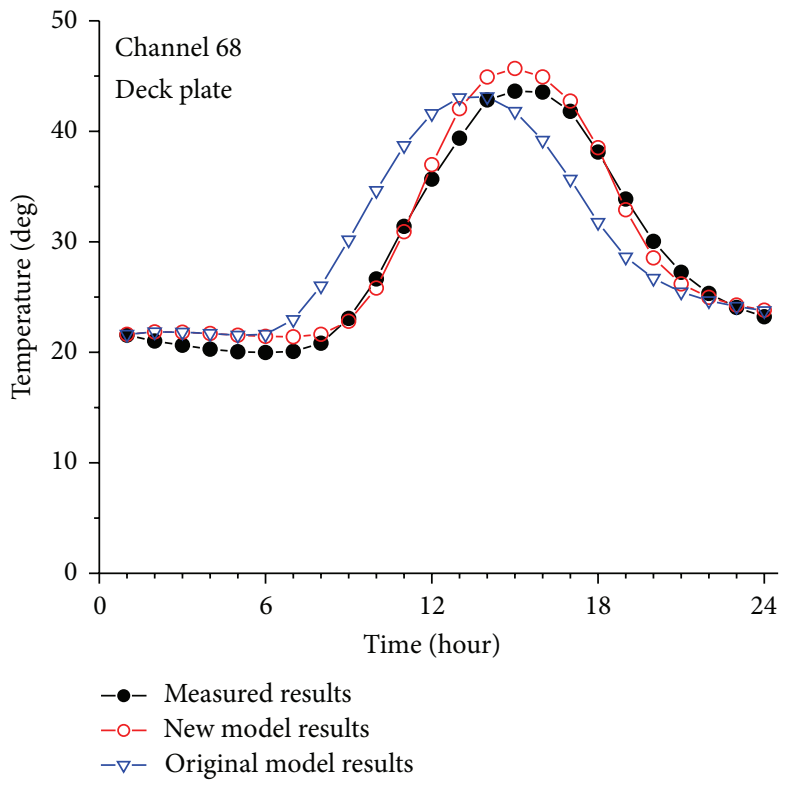

(c)

FIGURE 10: Comparison of the measured and simulated temperature in spring (April, 18, 2005). 


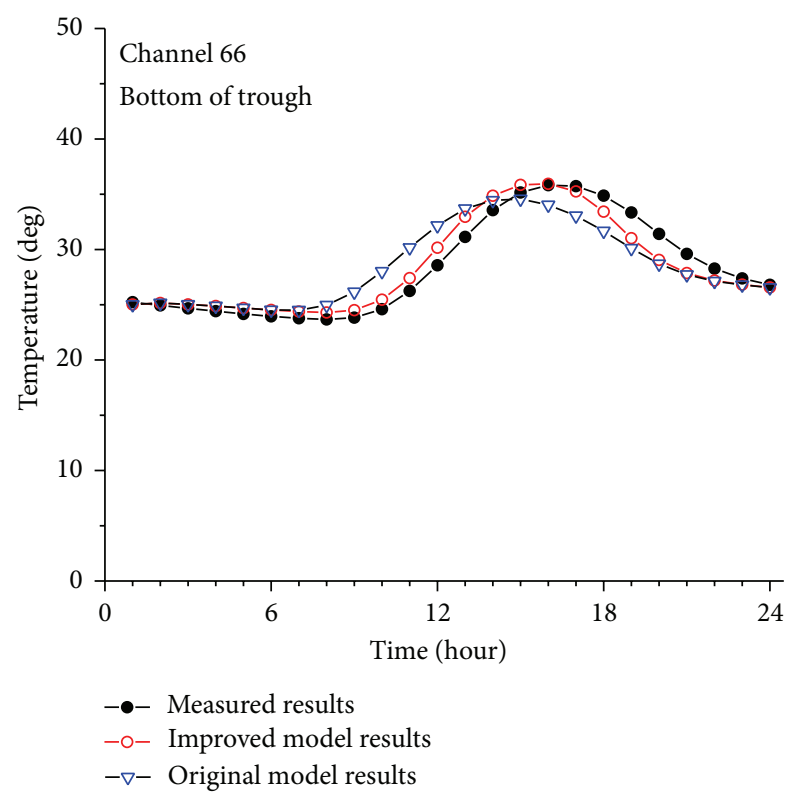

(a)

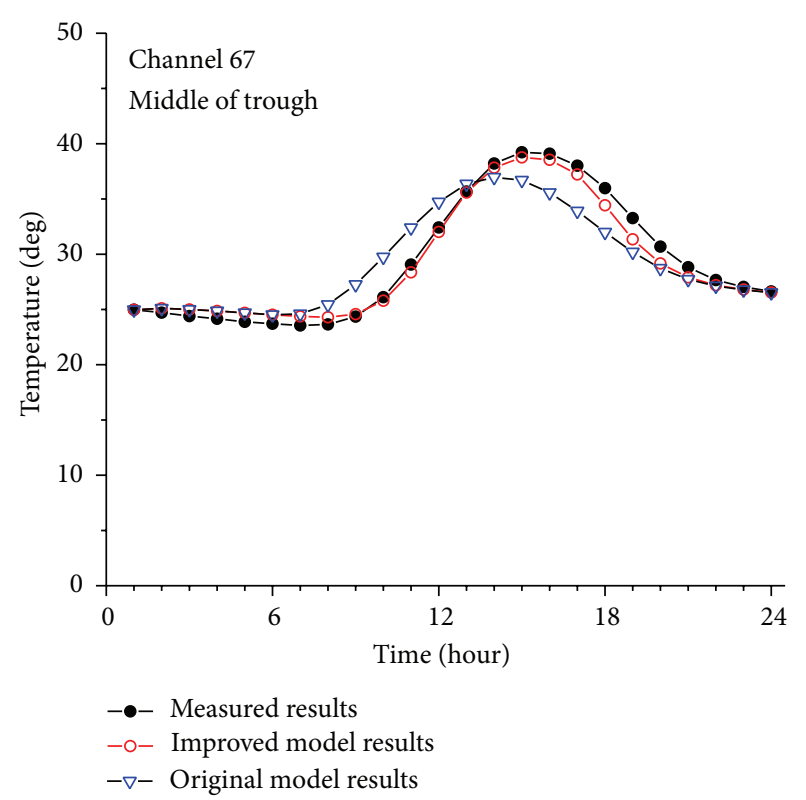

(b)

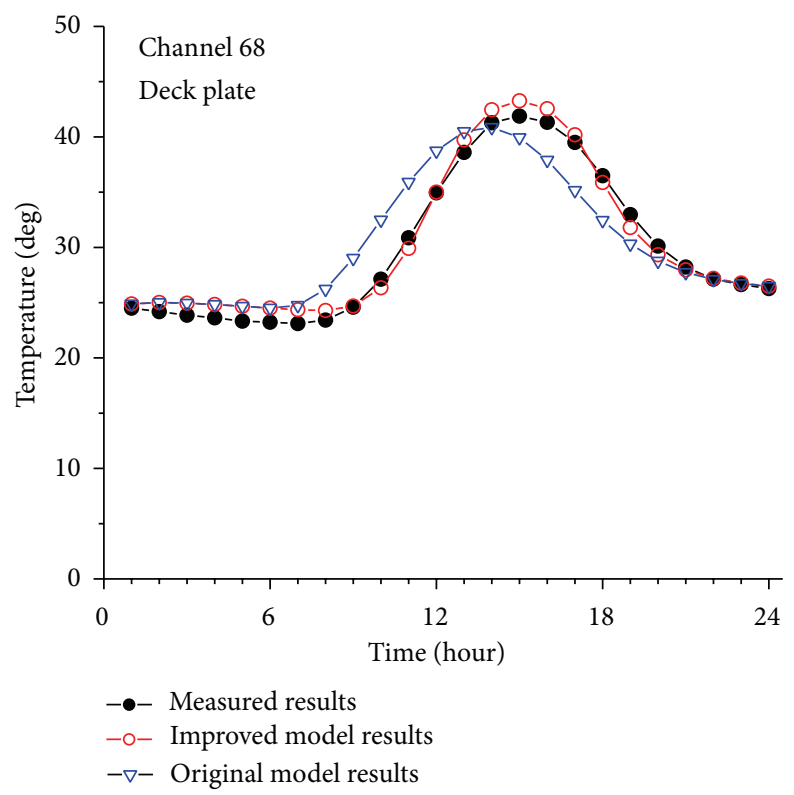

(c)

FIGURE 11: Comparison of the measured and simulated temperature in autumn (October, 27, 2005).

the omission of accessory components. The cross frame is enclosed by the deck plates and corrugate sheets and the heat exchange occurs between the plates and the section frame. Therefore, the temperature measured at the interface between the cross frame and enclosed plates (sheets) is used as a thermal boundary condition for heat transfer computation. Other surfaces of the deck plates and corrugated sheets are exposed to air and do not receive solar radiation directly. Figure 13 displays the temperature variations of many deck plates on the upper chord of the cross frame on July, 13, 2005. The calculated temperature variations on the upper chord are compared with the measured results as shown in Figure 13. It can be found that the numerical results agree very well with the measurement counterparts at different times. Similar observations can be made from components of the upper left chord, lower chord, and vertical truss members. The results are not shown here due to page limitation.

Temperature variations of deck plates on the bottom chord in summer are displayed in Figure 14. It is noted that the deck plates on the bottom chord cannot receive direct solar radiation due to the shelter of the deck module. Therefore, the heat transfer of these components is dominantly 


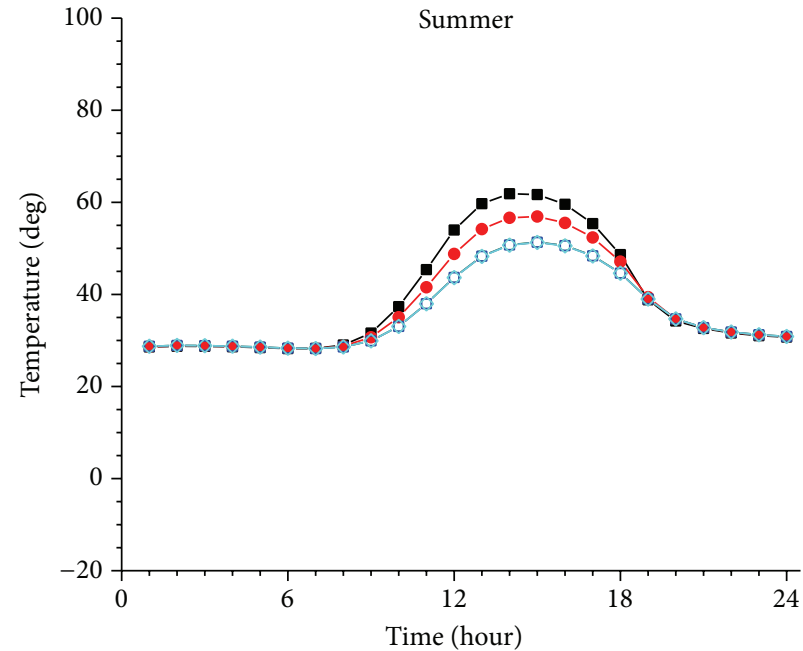

--- Top of asphalt cover $\quad-\square-$ Middle of steel plate - - Middle of asphalt cover $\quad-\diamond-$ Bottom of steel plate - - Interface of cover and plate

(a)

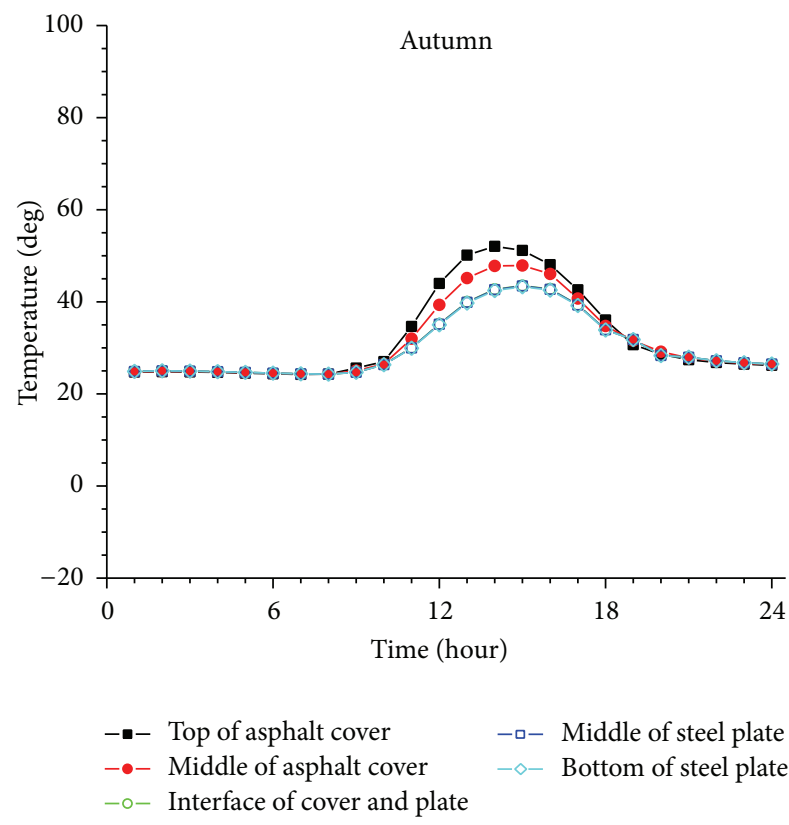

(c)
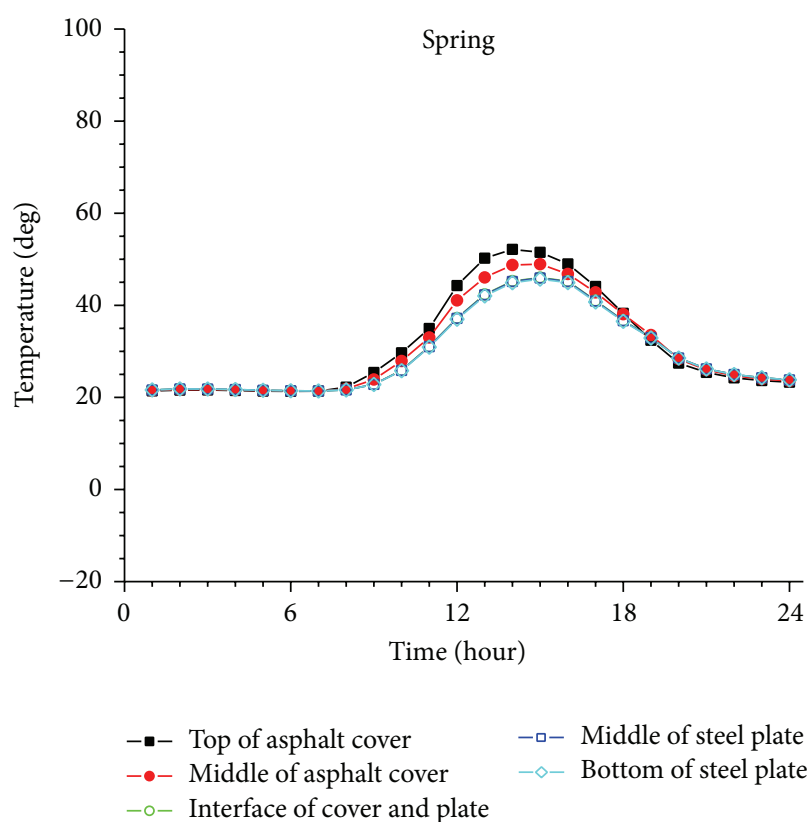

(b)

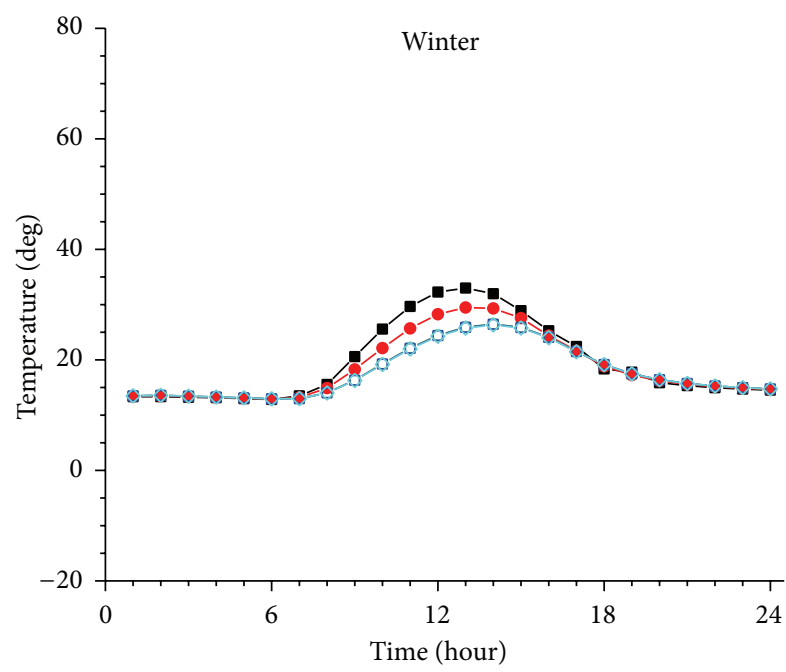

$\begin{array}{ll}\text {--- Top of asphalt cover } & -\square-\text { Middle of steel plate } \\ \text { - - } \text { Middle of asphalt cover } & -\diamond-\text { Bottom of steel plate } \\ \text { - }- \text { Interface of cover and plate } & \end{array}$

(d)

FIgURE 12: Temperature gradients of the deck plates at Detail 12.

controlled by the ambient temperature and flowing air. Therefore, it is clearly found from Figure 14 that the maximum temperatures of channels 15 and 25 are much smaller than those on the deck plates on the upper chord, which are exposed to the sun and receive direct solar radiation during the day. In addition, the variation ranges of daily temperature of the channels 15 and 25 are no more than $4^{\circ} \mathrm{C}$ for the whole day, which is also much smaller than those of the deck plates on the upper chords. Temperature variations of corrugated sheets in summer are displayed in Figure 15. Channel 38 is located on the upper corrugated sheet and it can receive direct solar radiation. However, channel 42 is located on the bottom corrugated sheet and it can only receive the diffuse radiation and reflected radiation instead of the direct radiation. Therefore, the maximum temperature of the channels 38 and 42 are $35.47^{\circ} \mathrm{C}$ and $33.18^{\circ} \mathrm{C}$, respectively. The former is larger than the latter by about $2.3^{\circ} \mathrm{C}$. It is clear that the predicted temperature variations agree well with those 


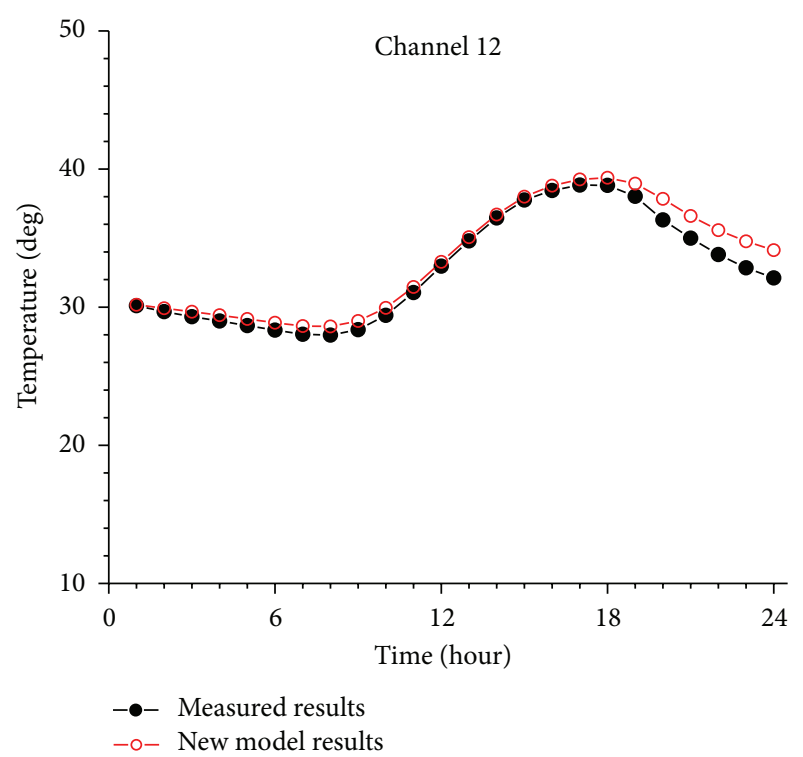

(a)

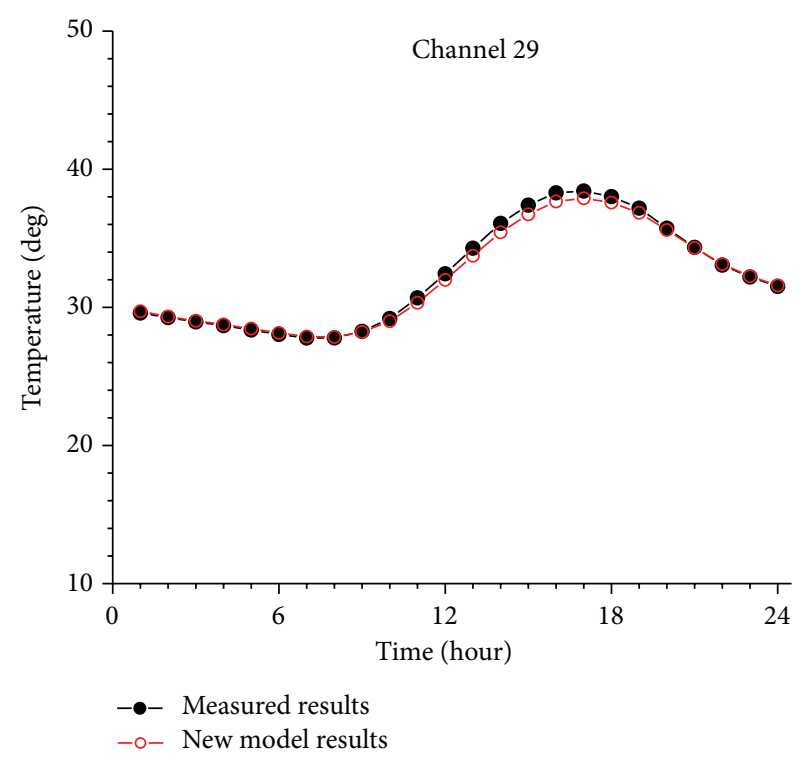

(c)

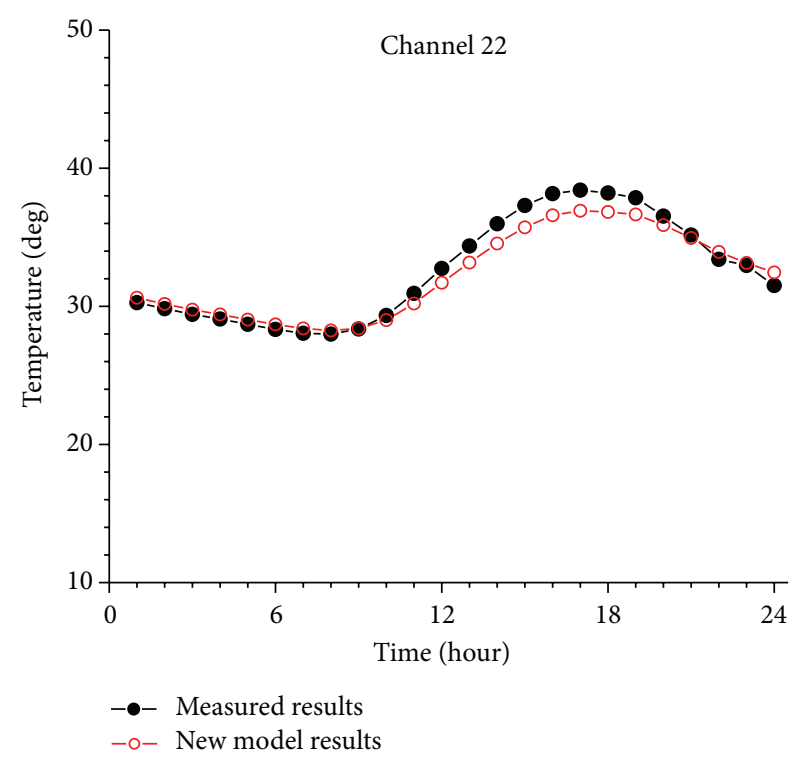

(b)

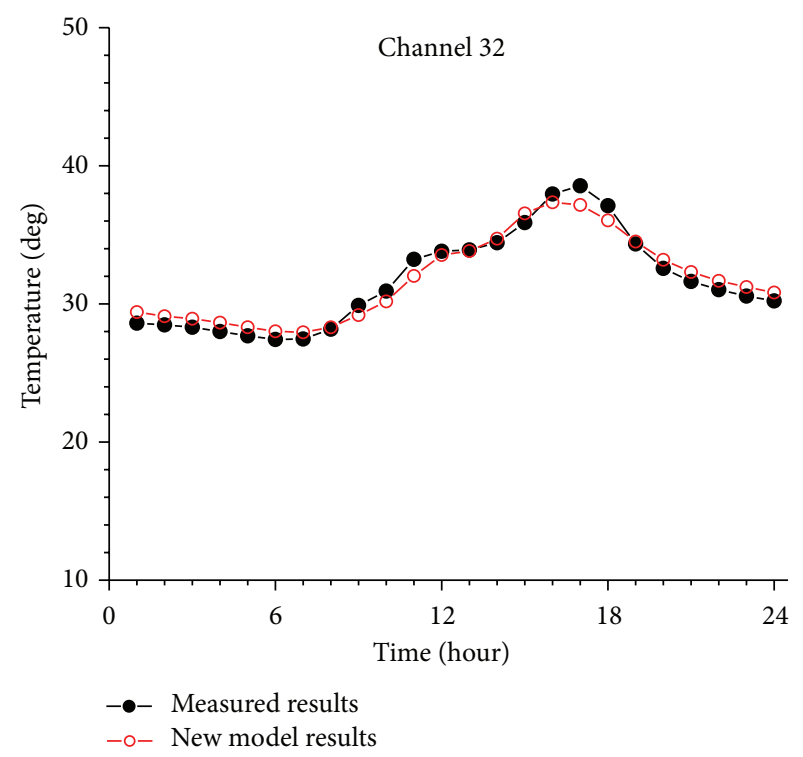

(d)

FIGURE 13: Temperature variations of deck plates on the upper chord (July, 17, 2005).

from field measurement no matter where the sensors are located, which demonstrate the validity and effectiveness of the proposed new solar radiation model.

\section{Concluding Remarks}

The thermal loading of a bridge deck plate is actively investigated in this study. A new solar radiation model for bridges is proposed to consider the shelter effects induced by cloud, mountains, and surrounding civil engineering structures. Fine finite element models of deck plates and corrugate sheets are constructed to examine the temperature distributions and thermal loading of bridge components. The feasibility and validity of the proposed new solar radiation model are examined through detailed numerical simulation and comparison.

The made observations indicate that by using the proposed approach, the simulated temperature in the summer at the testing points agrees with the measurement very well, which validates the effectiveness of the proposed solar radiation model and the heat transfer analysis. The maximum temperature of the bottom of the deck plate is larger than that of steel trough and the minimum temperatures at different parts of the deck plate are quite close to each other. Similar to the observations made for a summer day, the simulated temperature distributions using the new solar radiation model agree well with those from field measurement. It should be pointed out that the parameters and results are valid only 


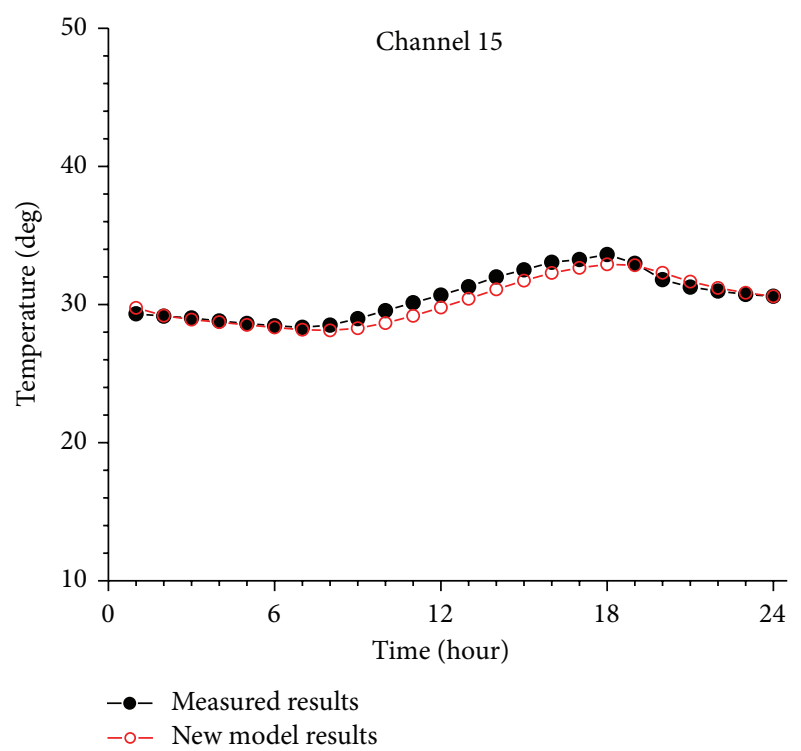

(a)

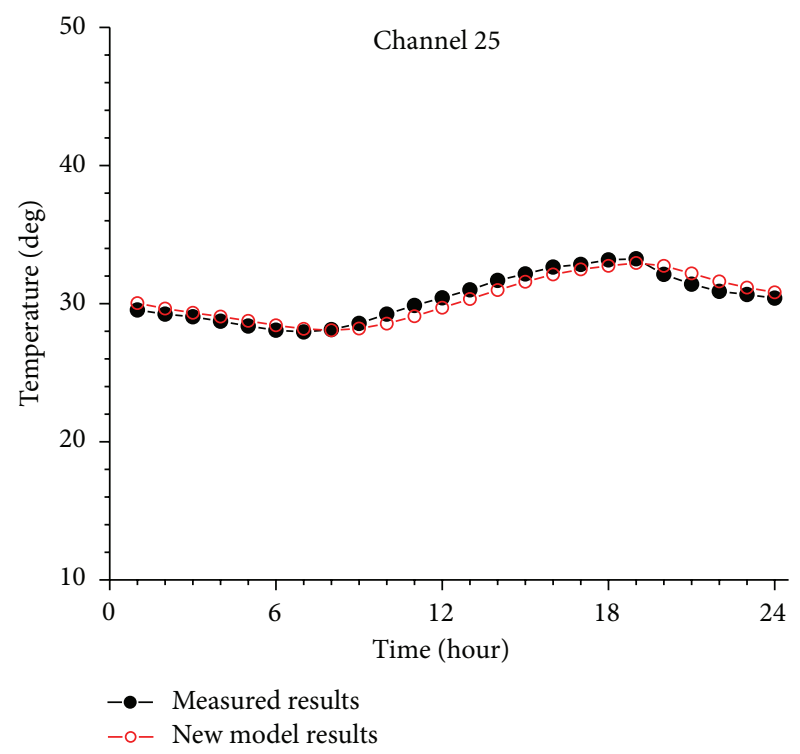

(b)

FIgURE 14: Temperature variations of deck plates on the bottom chord (July, 17, 2005).

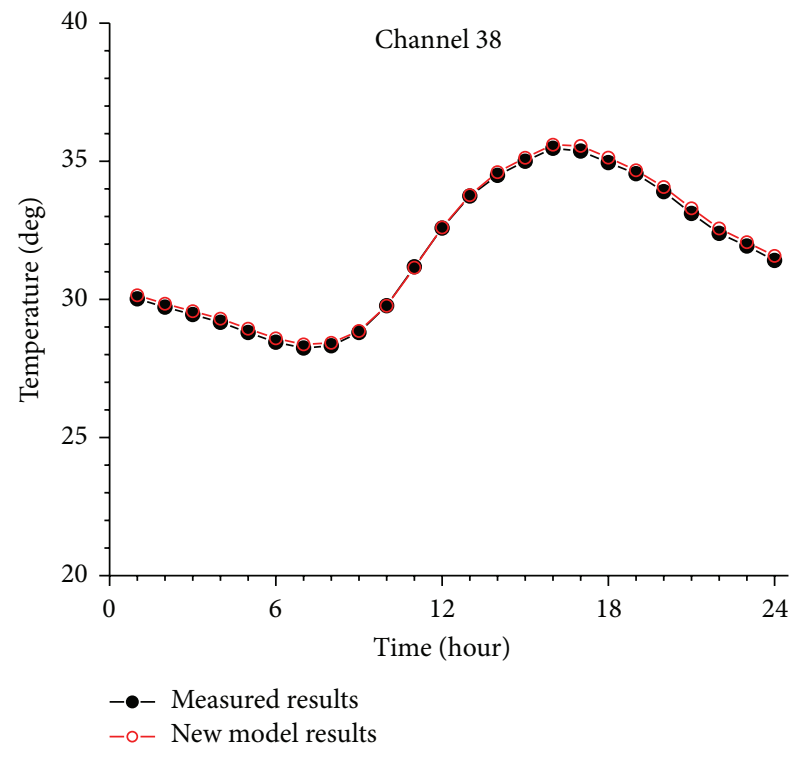

(a)

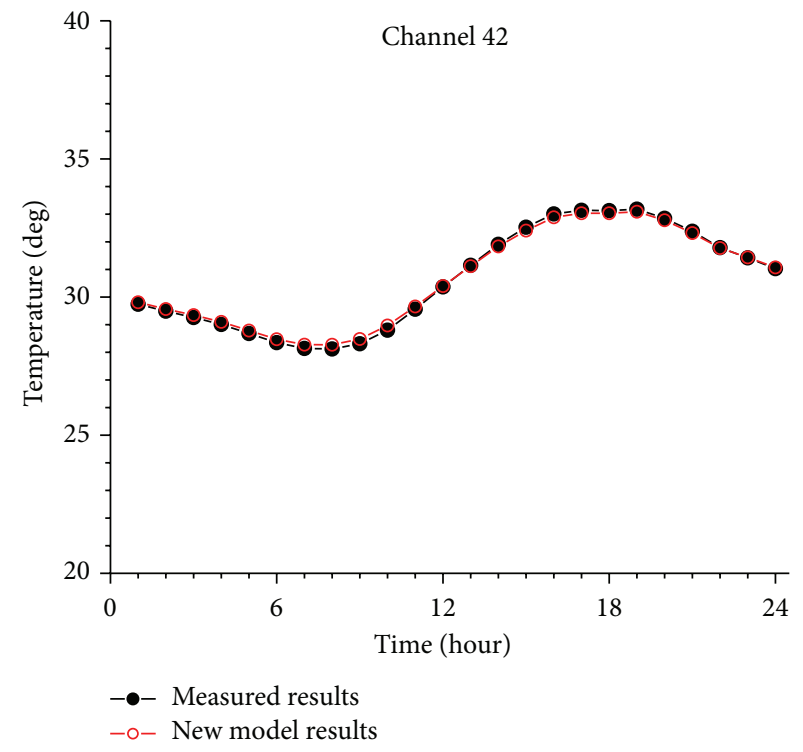

(b)

Figure 15: Temperature variations of corrugated sheets (July, 17, 2005).

for the example structure examined in this study. For other structures with different parameters, the methodology for the solar radiation and thermal loading demonstrated in this study is still valid.

\section{Conflict of Interests}

The authors declare that there is no conflict of interests regarding the publication of this paper.

\section{Acknowledgments}

The authors are grateful for the financial support from the National Natural Science Foundation of China (Grant 51178366), the Technological Project of the Chinese Southern Power Grid Co. Ltd. (Grant K-GD2013-0222), the Fundamental Research Funds for the Central Universities (WUT, 2013II-015), and the Fok Ying-Tong Education Foundation (Grant 131072). 


\section{References}

[1] G. D. Zhou and T. H. Yi, "Thermal load in large-scale bridges: a state-of-the-art review," International Journal of Distributed Sensor Networks, vol. 2013, Article ID 217983, 17 pages, 2013.

[2] T. Yi, H. Li, and M. Gu, "Full-scale measurements of dynamic response of suspension bridge subjected to environmental loads using GPS technology," Science China Technological Sciences, vol. 53, no. 2, pp. 469-479, 2010.

[3] B. Chen, Y. L. Xu, and X. Zhao, "Integrated vibration control and health monitoring of building structures: a time-domain approach," Smart Structures and Systems, vol. 6, no. 7, pp. 811833, 2010.

[4] Y. Lei, Y. Jiang, and Z. Xu, "Structural damage detection with limited input and output measurement signals," Mechanical Systems and Signal Processing, vol. 28, pp. 229-243, 2012.

[5] B. Chen, Z. W. Chen, Y. Z. Sun, and S. L. Zhao, "Condition assessment on thermal effects of a suspension bridge based on SHM oriented model and data," Mathematical Problems in Engineering, vol. 2013, Article ID 256816, 18 pages, 2013.

[6] W. Zuk, "Thermal behaviour of composite bridges-insulated and uninsulated," Highway Research Record, no. 76, pp. 231-253, 1965.

[7] M. W. R. Capps, The Thermal Behaviour of the Beachley Viaduct/ Wye Bridge, TRRL Report LR 234, Ministry of Transport, Road Research Laboratory, Crowthorne, UK, 1968.

[8] A. Churchward and Y. J. Sokal, "Prediction of temperatures in concrete bridges," Journal of Structural Division, vol. 107, no. 11, pp. 2163-2176, 1981.

[9] M. J. N. Priestley, "Design of concrete bridges for thermal gradients," ACI Journal, vol. 75, no. 5, pp. 209-217, 1978.

[10] F. Kehlbeck, Einfluss der Sonnenstrahlung bei Bruckenbauwerken, Werner, Dusseldorf, Germany, 1975.

[11] M. M. Elbadry and A. Ghali, "Temperature variation in concrete bridges," Journal of Structural Engineering, vol. 109, no. 10, pp. 2355-2374, 1983.

[12] F. A. Branco and P. A. Mendes, "Thermal actions for concrete bridge design," Journal of Structural Engineering, vol. 119, no. 8, pp. 2313-2331, 1993.

[13] Y. Lei, C. Liu, Y. Q. Jiang, and Y. K. Mao, "Substructure based structural damage detection with limited input and output measurements," Smart Structures and Systems, vol. 12, no. 6, pp. 619-640, 2013.

[14] Y. L. Xu and B. Chen, "Integrated vibration control and health monitoring of building structures using semi-active friction dampers: part I-methodology," Engineering Structures, vol. 30, no. 7, pp. 1789-1801, 2008.

[15] B. Chen and Y. L. Xu, "Integrated vibration control and health monitoring of building structures using semi-active friction dampers: part II-numerical investigation," Engineering Structures, vol. 30, no. 3, pp. 573-587, 2008.

[16] M. A. Shahawy and M. Arockiasamy, "Analytical and measured strains in sunshine skyway bridge. II," Journal of Bridge Engineering, vol. 1, no. 2, pp. 87-97, 1996.

[17] Y. Fu and J. T. DeWolf, "Effect of differential temperature on a curved post-tensioned concrete bridge," Advances in Structural Engineering, vol. 7, no. 5, pp. 385-397, 2004.

[18] Y. L. Xu, B. Chen, C. L. Ng, K. Y. Wong, and W. Y. Chan, "Monitoring temperature effect on a long suspension bridge," Structural Control and Health Monitoring, vol. 17, no. 6, pp. 632653, 2010.
[19] Y. Xia, B. Chen, S. Weng, Y. Q. Ni, and Y. L. Xu, “Temperature effects on variation properties of civil structures: a review and case studies," Journal of Civil Structural Health Monitoring, vol. 2, no. 1, pp. 29-46, 2012.

[20] Y. Xia, B. Chen, X.-Q. Zhou, and Y.-L. Xu, "Field monitoring and numerical analysis of Tsing Ma Suspension Bridge temperature behavior," Structural Control and Health Monitoring, vol. 20, no. 4, pp. 560-575, 2013.

[21] K. Y. Wong, C. K. Lau, and A. R. Flint, "Planning and implementation of the structural health monitoring system for cablesupported bridges in Hong Kong," in Nondestructive Evaluation of Highways, Utilities, and Pipelines IV, vol. 3995 of Proceedings of SPIE, pp. 266-275, Newport Beach, Calif, USA, March 2000.

[22] K. Y. Wong, D. K. L. Man, and K. W. Y. Chan, "Thermal load and response monitoring of Ting Kau (Cable-Stayed) bridge," in Proceedings of the International Conference on Innovation and Sustainable Development of Civil Engineering in the 21st Century, pp. 249-252, Beijing, China, August 2002.

[23] M. Tong, L. G. Tham, F. T. K. Au, and P. K. K. Lee, "Numerical modelling for temperature distribution in steel bridges," Computers and Structures, vol. 79, no. 6, pp. 583-593, 2001.

[24] F. T. K. Au, L. G. Tham, M. Tong, and P. K. K. Lee, “Temperature monitoring of steel bridges," in Health Monitoring and Management of Civil Infrastructure Systems, vol. 4337 of Proceedings of SPIE, pp. 282-291, Newport Beach, Calif, USA, March 2001.

[25] C. L. Roberts-Wollman, J. E. Breen, and J. Cawrse, "Measurements of thermal gradients and their effects on segmental concrete bridge," Journal of Bridge Engineering, vol. 7, no. 3, pp. $166-174,2002$.

[26] S. L. Desjardins, N. A. Londoño, D. T. Lau, and H. Khoo, "Realtime data processing, analysis and visualization for structural monitoring of the confederation bridge," Advances in Structural Engineering, vol. 9, no. 1, pp. 141-157, 2006.

[27] W. M. Rohsenow, Handbook of Heat Transfer Applications, McGraw-Hill, New York, NY, USA, 1988.

[28] ANSYS 11.0, ANSYS Inc., Southpointe, Pa, USA, 2010.

[29] T.-H. Yi, H.-N. Li, and M. Gu, "Optimal sensor placement for structural health monitoring based on multiple optimization strategies," Structural Design of Tall and Special Buildings, vol. 20, no. 7, pp. 881-900, 2011. 


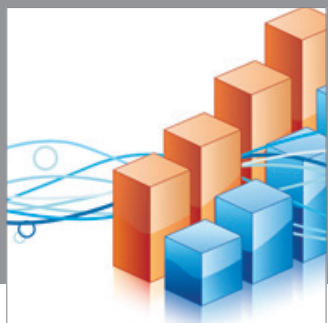

Advances in

Operations Research

mansans

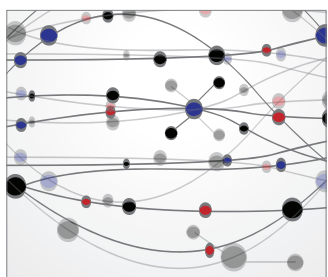

The Scientific World Journal
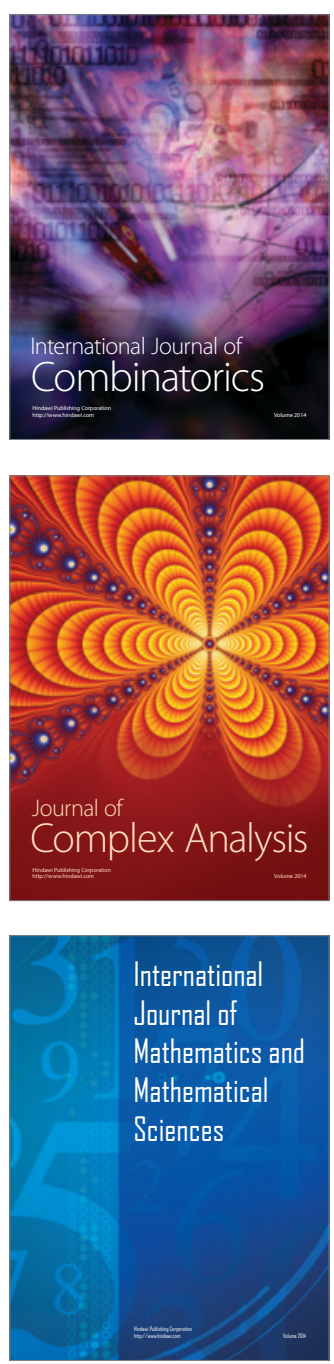
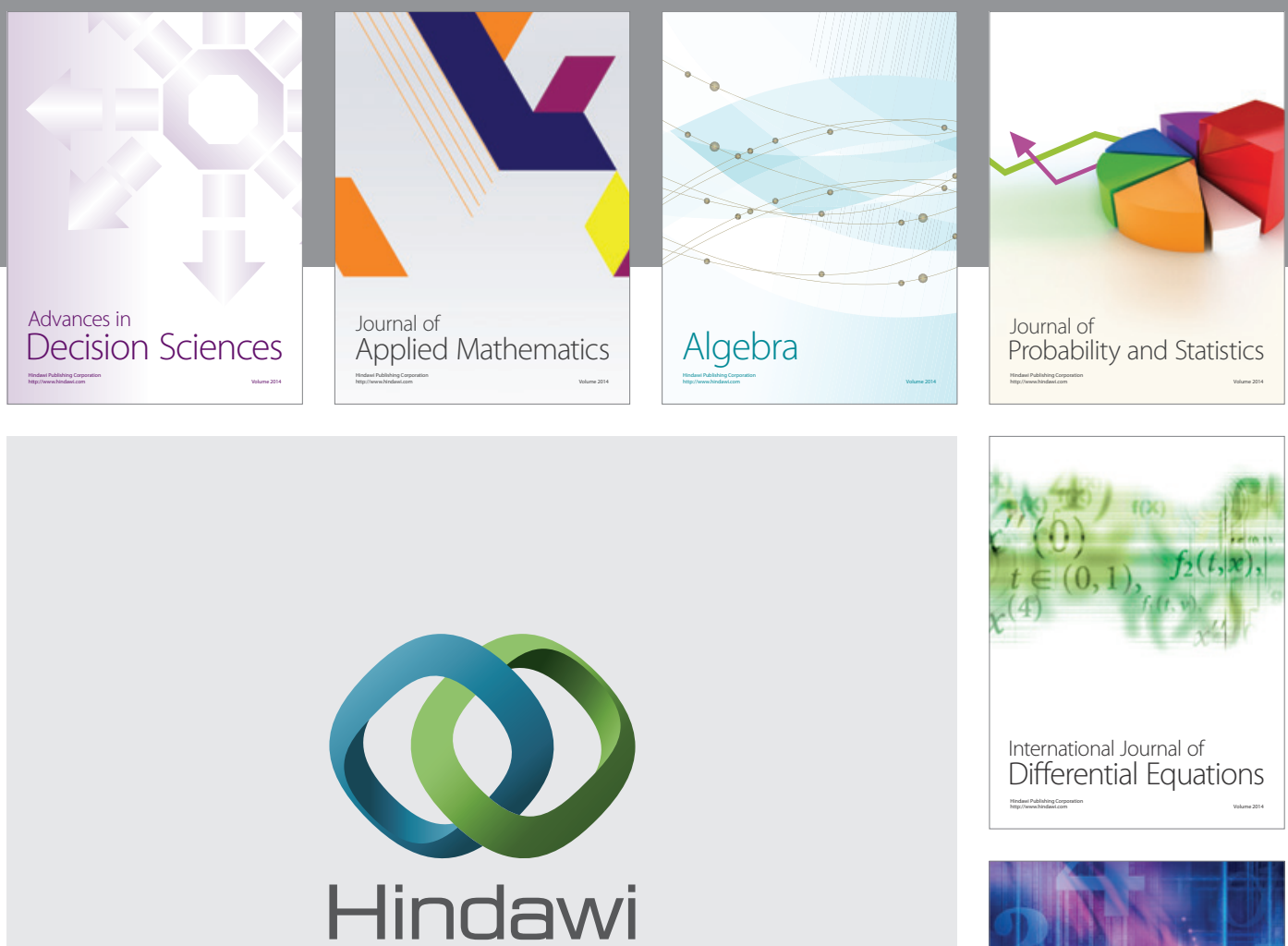

Submit your manuscripts at http://www.hindawi.com
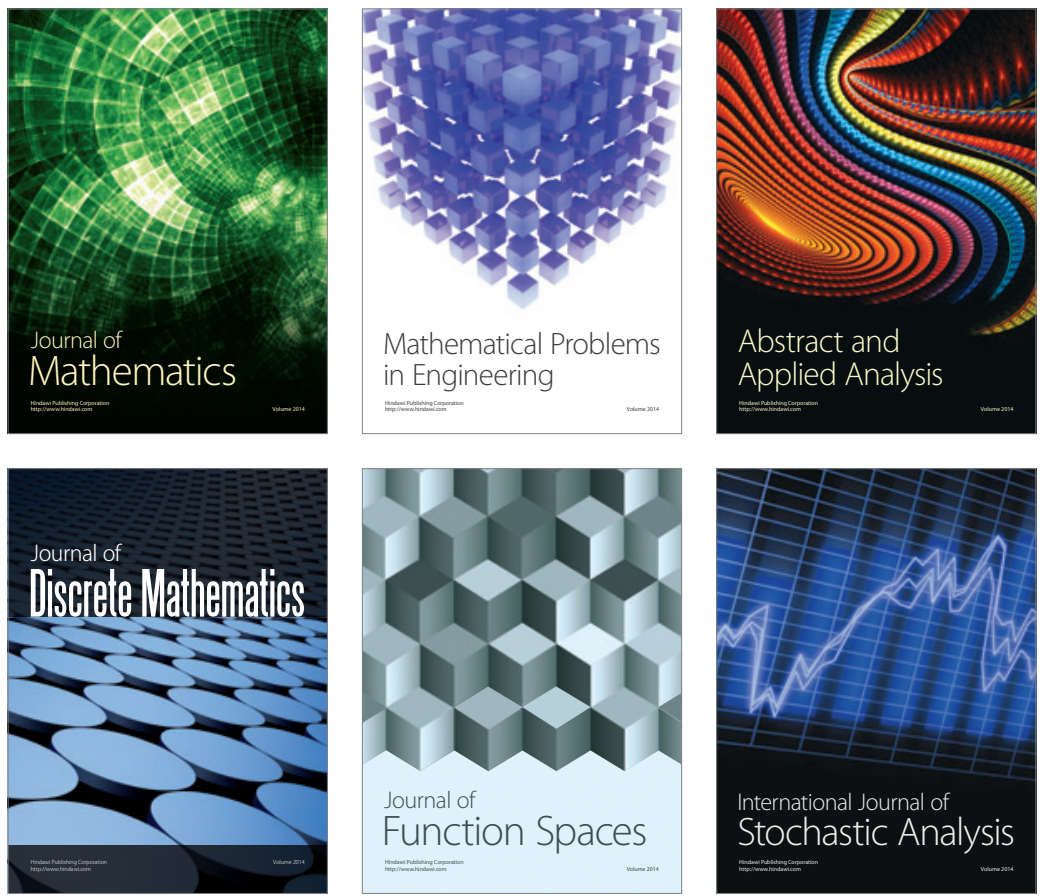

Journal of

Function Spaces

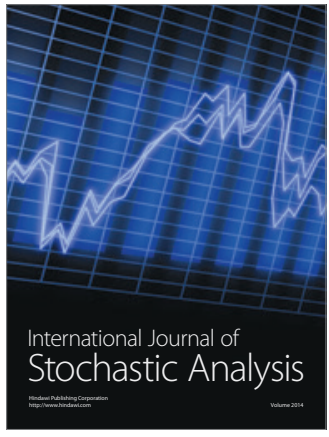

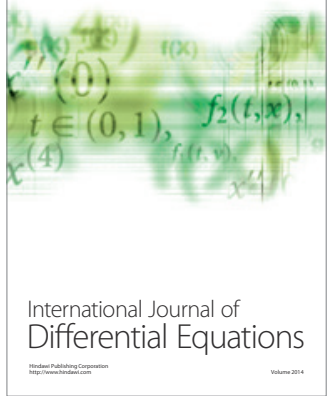
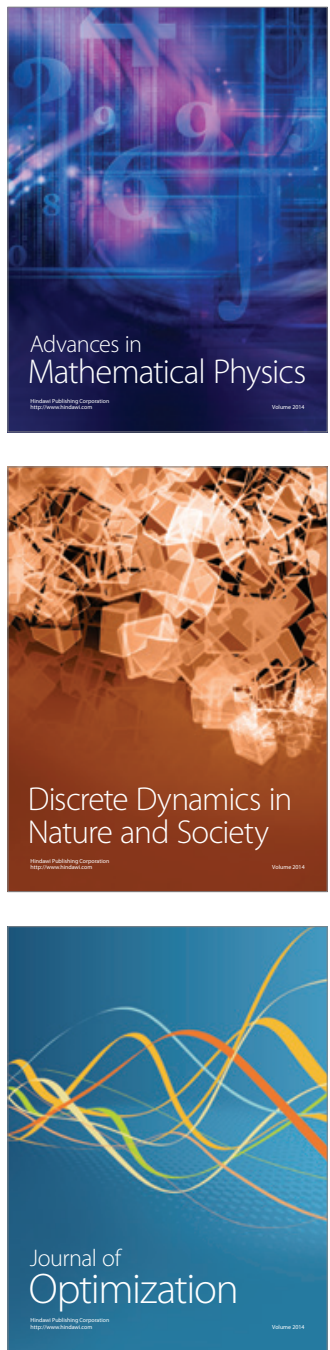